Dixis Figueroa Pedraza ${ }^{1}$

Tarciana Nobre de Menezes ${ }^{2}$

\section{Questionários de Frequência de Consumo Alimentar desenvolvidos e validados para população do Brasil: revisão da literatura}

\author{
Food Frequency Questionnaire developed and validated \\ for the Brazilian population: a review of the literature
}

${ }^{1}$ Departamento de Enfermagem, Universidade Estadual da Paraíba. Av. das Baraúnas 351/Campus I/Prédio dos Mestrados, Bodocongó. 58109-753 Campina Grande PB Brasil.

dixisfigueroa@gmail.com 2 Departamento de Fisioterapia, Universidade Estadual da Paraíba.

\begin{abstract}
Assessing food intake is a challenge for researchers given the inherent complexity of the issue. One of the methods used in epidemiological studies is the Food Frequency Questionnaire (FFQ). The scope of this paper was to identify studies that developed and/or validated the FFQ in Brazil, analyzing the methods used and the main results of the validation. The PubMed, LILACS and SciELO databases were researched for studies published prior to 2013 on the development and validation of the FFQ in Brazil. These studies were analyzed according to: i) the main methodological characteristics of the elaboration/validation process of the questionnaires; ii) the key results related to validation. Forty-one studies were assessed: 6 on the development of the FFQ; 18 on the development and validation of the FFQ; 17 on the validation of the FFQ. There were inter-regional differences in the publications and methodological differences in the elaboration and validation of the FFQ. Adults and adolescents were the groups most covered for the validation of the FFQ, though specific studies for children $<5$ years of age were not found. The methodological rigor and statistical results guarantee the suitability of the validation of the FFQ for the target populations, with high correlations for energy, carbohydrates, fibers, calcium and vitamin $C$.
\end{abstract}

Key words Food consumption, Validation studies
Resumo Avaliar a ingestão alimentar é um desafio aos pesquisadores devido à complexidade envolvida, sendo, para isso, usado em estudos epidemiológicos o Questionário de Frequência de Consumo Alimentar (QFCA). Este artigo identificou os estudos que desenvolveram e/ou validaram QFCA no Brasil, analisando os métodos e os principais resultados. Foram consultadas as bases de dados PubMed, Lilacs e SciELO, e incluídos artigos publicados até 2013 sobre o desenvolvimento e/ou validação do QFCA na população brasileira, os quais foram caracterizados e analisados de acordo com: i) as principais características metodológicas do processo de elaboração e validação e ii) os principais resultados relacionados com a validação. Foram revisados 41 artigos, dos quais seis tratavam do desenvolvimento do QFCA, 17 da validação e 18 de ambos. Houve diferenças inter-regionais nas publicações e metodológicas tanto na elaboração dos questionários quanto na validação. Nos estudos de validação do QFCA, adultos e adolescentes foram os grupos mais contemplados, não sendo encontrados para crianças menores de cinco anos. O rigor metodológico e os resultados estatísticos satisfatórios observados garantem a adequação dos QFCA, validados para as respectivas populações alvo, com altas correlações para energia, carboidrato, fibras, cálcio e vitamina $C$.

Palavras-chave Consumo de alimentos, Estudos de validação 


\section{Introdução}

A avaliação da dieta humana tem sido fonte de desafios para os pesquisadores há anos, haja vista a complexidade de avaliar de forma qualitativa e quantitativa a ingestão dos alimentos ${ }^{1-3}$. Sua importância para a pesquisa em nutrição e saúde, e para o desenvolvimento de programas não governamentais e governamentais, é indubitável, tendo em vista que possibilita a caracterização do nível de risco e vulnerabilidade às carências e excessos nutricionais. Os dados gerados sobre ingestão alimentar constituem uma ferramenta fundamental para estabelecer as condições de saúde de uma população, auxiliando na avaliação da associação entre dieta, nutrição e saúde, a detecção de deficiências de nutrientes e a caracterização do nível de risco e de vulnerabilidade da população ${ }^{3-5}$.

Diferentes métodos podem ser utilizados na avaliação da ingestão alimentar, dentre os quais se destacam o questionário de frequência de consumo alimentar (QFCA), o recordatório de 24 horas (R24h), o registro ou diário alimentar (RA/DA), a história dietética e o método de inventário ${ }^{3,4}$. Devido às limitações de cada método, a escolha do instrumento para medir a informação dietética não constitui tarefa fácil. A escolha do método deve estar fundamentada em vários fatores: os objetivos do estudo, a característica do grupo populacional a ser estudado, os alimentos e nutrientes de interesse, os recursos disponíveis, o desenho metodológico do estudo ${ }^{5,6}$. Além disso, a escolha do método deve garantir que o mesmo forneça dados válidos, reprodutíveis e comparáveis $^{3}$. Por reunir as características anteriores, o QFCA é um método comumente utilizado para verificar a associação de dieta e doença ${ }^{7}$.

A lista de alimentos e a frequência de ingestão dos mesmos constituem aspectos primordiais de um QFCA. Dessa forma, os indivíduos ao serem questionados sobre a ingestão alimentar, informam a frequência e o intervalo de tempo. Portanto, a qualidade com que o QFCA irá cumprir seus objetivos dependerá do nível de acurácia do relato da frequência de ingestão alimentar e da adequação da lista de alimentos ${ }^{8,9}$.

$\mathrm{Na}$ perspectiva de obter um QFCA capaz de medir adequadamente a ingestão alimentar no Brasil, a construção, a adequação e a validação constituem uma importante área de estudo, dando origem a diversos instrumentos validados para populações e objetivos específicos ${ }^{9}$. O objetivo do presente artigo foi identificar os estudos que desenvolveram e/ou validaram questionários de frequência de consumo alimentar no Brasil, analisando os métodos adotados para esses fins e principais resultados da validação. Além de possibilitar as escolhas dos instrumentos mais adequados e verificar a utilidade de tais questionários no país, esperamos que os resultados possam subsidiar as pesquisas para a melhoria dos procedimentos de determinação da ingestão alimentar de populações, considerando as variações sociais e culturais que permeiam os hábitos alimentares.

\section{Metodologia}

Foi realizada uma revisão da literatura, procurando-se capturar artigos científicos em idioma inglês ou português sobre QFCA desenvolvidos e/ ou validados no Brasil e publicados até 2013. Para a identificação dos artigos, realizou-se uma busca nas bases de dados PubMed (National Library of Medicine, Estados Unidos), Lilacs (Literatura Latino-americana e do Caribe em Ciências da Saúde) e SciELO (Scientific Electronic Library Online). A busca bibliográfica foi realizada por dois revisores usando a combinação dos descritores (estudos de validação OR validade) AND (consumo de alimentos) e seus correspondentes em inglês (validation studies OR validity) AND (food consumption). No caso da busca no PubMed, o descritor Brazil também foi usado. Para o cômputo do total de estudos identificados foi verificada a duplicação dos mesmos entre as bases de dados, sendo cada artigo contabilizado somente uma vez.

A partir dos estudos identificados, foram selecionados aqueles que parecessem preencher os critérios para sua inclusão, considerando a leitura dos títulos e resumos pelos revisores. $\mathrm{Na}$ sequência, todos os artigos selecionados foram avaliados pelos revisores considerando a leitura $\mathrm{e}$ análise criteriosa do texto na íntegra (artigos não disponíveis online foram comprados). Após esta ação, os artigos foram classificados em excluídos ou incluídos considerando os critérios estabelecidos para estes fins:

- critérios de inclusão: estudos de desenvolvimento do QFCA, estudos de validação de QFCA, estudos em população brasileira;

- critérios de exclusão: estudos em animais; artigos de revisão; livro/tese/carta ao editor; estudos de validação de outros instrumentos; estudos de avaliação físico-química, higiênica ou organoléptica de alimentos ou de rotulagem de alimentos; estudos de avaliação de processos tecnológicos; estudos realizados fora do Brasil; estudos de análise do consumo de alimentos. 
Posteriormente, nos artigos classificados como incluídos, as listas de referências bibliográficas foram consultadas com a finalidade de identificar outros estudos que aparentemente atendessem aos critérios de inclusão. Os estudos identificados desta maneira foram lidos na íntegra pelos revisores e avaliados com os mesmos critérios dos artigos previamente selecionados, sendo incluídos na revisão aqueles nos quais foi confirmado o atendimento aos critérios de seleção. Nos casos dos artigos que tratavam exclusivamente da validação, a sua inclusão foi realizada apenas quando o artigo sobre o respectivo QFCA desenvolvido, que serviu de referência, foi identificado.

Após definição de quais estudos seriam incluídos com base na busca eletrônica e na consulta às listas de referências bibliográficas, foram realizadas buscas específicas, nas mesmas bases de dados, pelo nome de autor, definido considerando sua participação como primeiro autor e/ou aqueles que constavam como autores de, no mínimo, dois artigos. Os trabalhos assim identificados foram submetidos aos mesmos procedimentos utilizados naqueles identificados por meio das listas de referências bibliográficas.

Tanto a busca inicial por descritores quanto a busca específica por autores foi atualizada em 19 de julho de 2014. As discrepâncias entre revisores na busca bibliográfica, na seleção dos estudos e na classificação dos artigos como incluídos ou excluídos, foram resolvidas por consenso. Essa observação foi válida, também, para os artigos identificados nas listas de referências bibliográficas e na busca específica por autores. Os artigos não disponíveis online foram comprados.

Os estudos selecionados foram caracterizados de acordo com os autores e ano de publicação, objetivo do estudo, tipo de questionário, amostra para elaborar a lista de alimentos e local da coleta dos dados. Após a caracterização inicial, as principais características metodológicas relacionadas com o processo de elaboração e validação dos questionários foram descritas, assim como os principais resultados relacionados com a validação.

Para a análise dos artigos que se propunham elaborar um instrumento de avaliação da dieta a partir da frequência alimentar, foram consideradas as etapas propostas por Colucci et al. ${ }^{6}$, que indicam: elaboração da lista de alimentos mais representativos e critérios para sua inclusão, definição do tamanho das porções, definição de tempo precedente, categorias para determinar a frequência de ingestão.
Para artigos com validação de questionários, esse processo foi analisado considerando os aspectos metodológicos propostos por Slater et al. ${ }^{2}$ : amostra utilizada para validação, método de referência e intervalo de aplicação, medidas de validade.

Para analisar os resultados da validação dos questionários, os itens avaliados foram classificados segundo Willett e Lenart ${ }^{7}$, que recomendam, no mínimo, um coeficiente de correlação de 0,4 entre o QFCA e o método de referência. Sendo assim, valores superiores ou iguais a 0,4 foram considerados para indicar alta correlação e valores inferiores para indicar baixa correlação. Considerando que os artigos apresentavam quantidade e formas diferentes de análises, as informações apresentadas neste estudo respeitaram a seguinte ordem: 1. de-atenuados e ajustados pela energia, 2. de-atenuados, 3. ajustados pela energia.

\section{Resultados}

Inicialmente foram identificados 114 estudos nas bases de dados. Foram classificados como incluídos, após análise dos critérios de inclusão e de exclusão, um total de 19 artigos. A estes, posteriormente, foram acrescentados 15 artigos identificados por meio das listas de referências bibliográficas e sete utilizando a busca específica por autores, os quais atenderam aos critérios de seleção. Do total de 41 estudos revisados, verificou-se que seis tratavam do desenvolvimento do QFCA, 18 do desenvolvimento e validação e 17 da validação. O fluxo relacionado com a seleção dos artigos encontra-se no Tabela 1.

O Quadro 1 mostra a distribuição dos 24 estudos que desenvolveram QFCA ${ }^{10-33}$ quanto aos parâmetros de caracterização adotados, dos quais 18 validados ${ }^{10-27}$ e seis sem validação ${ }^{28-33}$, até o momento da busca bibliográfica. Do total de 23 QFCA com a informação sobre o tipo de questionário, 13 são do tipo quantitativo ${ }^{11-13,15,16,19,20,22-24,26,31,33}$ e 10 são semiquantitati$\operatorname{vos}^{10,14,17,18,21,27-30,32}$

De acordo com o objetivo de estudo, alguns consideraram a condição patológica, como são os casos dos direcionados à análise da relação entre dieta e excesso de peso ${ }^{12}$, dieta e câncer de mama $^{16}$, e dieta e doenças não transmissíveis $^{13,27,30}$. Quanto ao ciclo da vida, para a elaboração das listas de alimentos, os estudos trabalharam com adultos ${ }^{10,12,13,15,21,23,30,33}$; adolescentes $^{14,18,28,32}$; crianças $^{25,29}$; adolescentes e adultos ${ }^{31}$; adultos e idosos 11,16,19,27; adolescentes, adultos e 


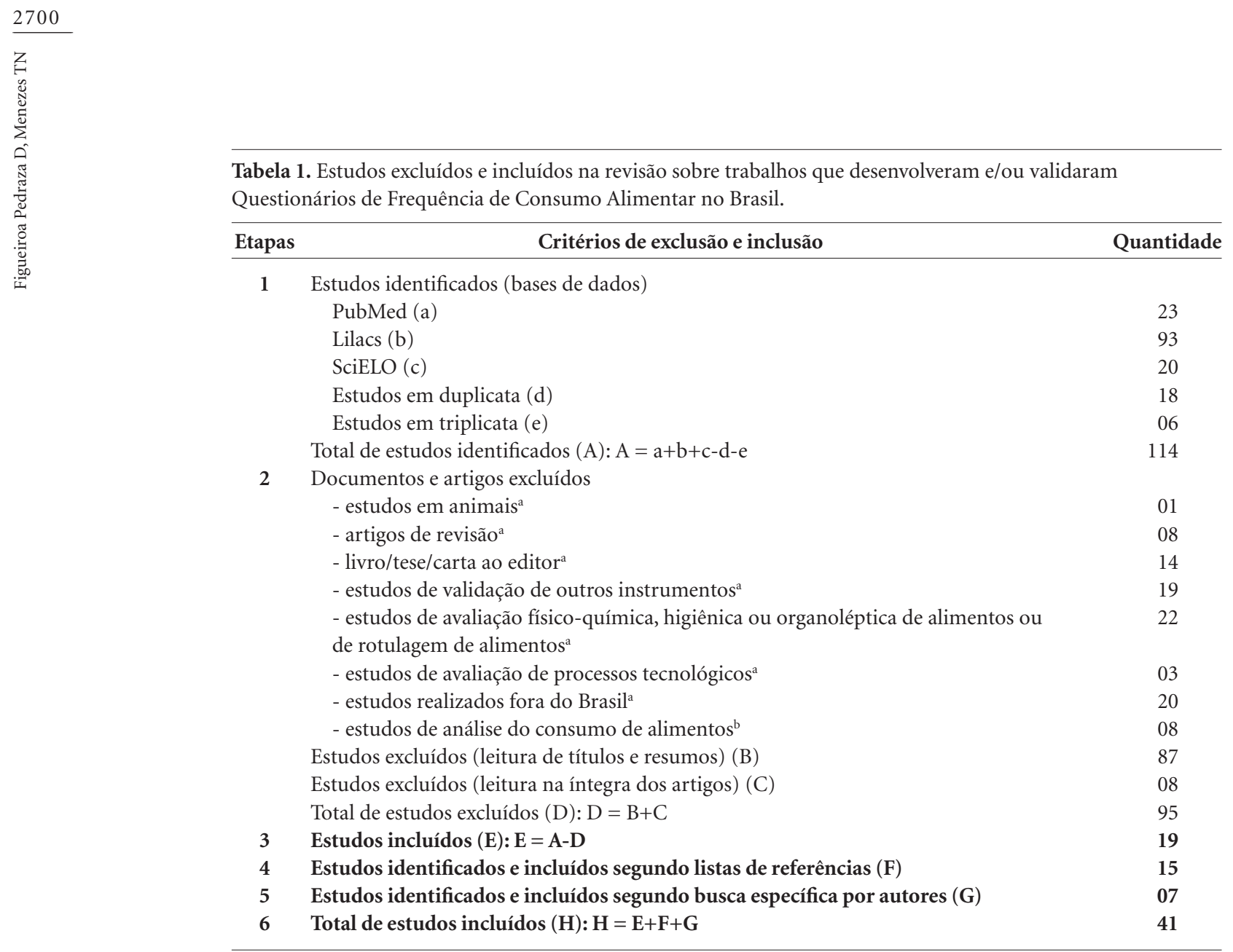

${ }^{a}$ Leitura de títulos e resumos / b Leitura na íntegra dos artigos.

idosos ${ }^{20}$; crianças, adolescentes, adultos e idosos ${ }^{17}$; gestantes $^{22,26}$. Com relação às regiões, observa-se que o Sudeste concentra a maior quantidade de estudos ${ }^{10-12,14,17-19,22,23,29,30,32}$, dos quais seis trataram da validação ${ }^{10-12,14,17,18}$. Um dos estudos trabalhou com universitários ${ }^{24} \mathrm{e}$ outro foi multicêntrico ${ }^{27}$.

As características metodológicas do processo de elaboração dos 24 QFCA desenvolvidas são apresentadas no Quadro 2. O R24h foi o instrumento mais utilizado para a elaboração das listas dos alimentos ${ }^{15-17,19-23,25,27,29-32}$. Para a elaboração da lista de alimentos mais representativos da dieta habitual dos indivíduos e de maior contribuição para a ingestão de nutrientes, os dados do Estudo Nacional de Despesa Familiar ${ }^{34}$ foram utilizados por Sichieri e Everhart ${ }^{10}$, e a estratégia proposta por Block et al. ${ }^{8,35,36}$ foi utilizada em 10 estudos $^{11,14,16,18,19,23,24,29,30,32}$. A estratégia sugerida por Willett e Lenart ${ }^{7}$ foi utilizada por Salvo e Gimeno $^{12}$ e Slater et al. ${ }^{14}$ (autores que também usaram a estratégia de Nelson ${ }^{37}$ ). Com o objetivo centrado no consumo de alimentos ricos em polifenóis, Vian et al. ${ }^{26}$ utilizaram a American database ${ }^{38}$ e o estudo de Faller e Fialho ${ }^{39}$. A estratégia proposta por Howe et al..$^{40}$ foi utilizada por Colucci et al..$^{29}$

Do total de estudos, a informação referente ao tamanho das porções alimentares habitualmente ingeridas não foi incluída nos QFCA desenvolvidos em três estudos ${ }^{15,25,28}$. Os períodos de seis meses $^{14,15,18,29,31,32}$ e de um ano ${ }^{10,11,19,29,27}$ foram as unidades de tempo precedentes mais comumente empregadas para estimar a ingestão habitual de alimentos. Os outros estudos que incluíram a informação adotaram períodos de tempo menores de seis meses ${ }^{12,17,28}$. Em 11 estudos ${ }^{13,16,20,21-26,30,33}$ essa informação não estava contida.

Quanto às categorias de frequência de ingestão, os questionários referem desde três ${ }^{12,13,17,22,24}$ até nove $\mathrm{e}^{15,30,31}$ categorias. No que se refere à quantidade de itens alimentares, os questionários desenvolvidos por Cardoso e Stocco ${ }^{11}$ e por Carvalho et al. ${ }^{28}$ se destacam por serem os que usaram maior e menor quantidade, respectivamente, com diferença marcante, se comparados com a maioria dos outros estudos. 
Quadro 1. Características dos estudos que desenvolveram Questionários de Frequência de Consumo Alimentar no Brasil.

\begin{tabular}{|c|c|c|c|c|}
\hline & Autores, ano & Objetivo do estudo & $\begin{array}{l}\text { Tipo de } \\
\text { questionário }\end{array}$ & $\begin{array}{c}\text { Amostra para elaborar a lista } \\
\text { de alimentos e local } \\
\text { da coleta dos dados }\end{array}$ \\
\hline & $\begin{array}{l}\text { Sichieri e } \\
\text { Everhart, } 1998^{10}\end{array}$ & $\begin{array}{l}\text { Desenvolver e validar um QFCA para } \\
\text { trabalhadores adultos. }\end{array}$ & Semiquantitativo & $\begin{array}{l}88 \text { funcionários de universidade } \\
\text { pública. Rio de Janeiro/RJ. }\end{array}$ \\
\hline & $\begin{array}{l}\text { Cardoso e Stocco, } \\
2000^{11}\end{array}$ & $\begin{array}{l}\text { Desenvolver um QFCA para avaliar } \\
\text { consumo de alimentos e nutrientes de } \\
\text { indivíduos de etnia japonesa. }\end{array}$ & Quantitativo & $\begin{array}{l}166 \text { adultos ( } 45 \text { a } 70 \text { anos). São } \\
\text { Paulo/SP. }\end{array}$ \\
\hline & $\begin{array}{l}\text { Salvo e Gimeno, } \\
2002^{12}\end{array}$ & $\begin{array}{l}\text { Desenvolver, validar e verificar a } \\
\text { reprodutibilidade de um QFCA para } \\
\text { população com excesso de peso. }\end{array}$ & Quantitativo & $\begin{array}{l}181 \text { pacientes obesos adultos } \\
\text { (informação dos prontuários). } \\
\text { São Paulo/SP. }\end{array}$ \\
\hline & $\begin{array}{l}\text { Ribeiro e } \\
\text { Cardoso, } 2002^{13}\end{array}$ & $\begin{array}{l}\text { Desenvolver um QFCA visando sua } \\
\text { adoção em programas de prevenção } \\
\text { e controle de doenças crônicas não } \\
\text { transmissíveis. }\end{array}$ & Quantitativo & $\begin{array}{l}212 \text { funcionários da } \\
\text { administração central de } \\
\text { Secretaria Estadual de Saúde. } \\
\text { São Paulo/SP. }\end{array}$ \\
\hline (5) & $\begin{array}{l}\text { Slater et al., } \\
2003^{14}\end{array}$ & $\begin{array}{l}\text { Desenvolver e validar um QFCA para } \\
\text { adolescentes. }\end{array}$ & Semiquantitativo & 200 adolescentes. São Paulo/SP. \\
\hline & $\begin{array}{l}\text { Fornés et al., } \\
2003^{15}\end{array}$ & $\begin{array}{l}\text { Desenvolver, validar e verificar a } \\
\text { reprodutibilidade de um QFCA para } \\
\text { trabalhadores de baixa renda e baixa } \\
\text { alfabetização. }\end{array}$ & Quantitativo & $\begin{array}{l}104 \text { trabalhadores ( } 18 \text { a } 60 \text { anos). } \\
\text { Goiânia/GO. }\end{array}$ \\
\hline 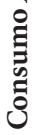 & Lima et al., $2003^{16}$ & $\begin{array}{l}\text { Desenvolver um QFCA para estudo } \\
\text { de caso-controle sobre dieta e câncer } \\
\text { de mama. }\end{array}$ & Quantitativo & $\begin{array}{l}100 \text { mulheres ( } 20 \text { a } 75 \text { anos). } \\
\text { João Pessoa/PB. }\end{array}$ \\
\hline & Sales et al., $2006^{17}$ & $\begin{array}{l}\text { Desenvolver um instrumento para } \\
\text { avaliação quantitativa e qualitativa } \\
\text { sobre ingestão dietética. }\end{array}$ & Semiquantitativo & $\begin{array}{l}119 \text { indivíduos ( } 01 \text { a } 80 \text { anos ou } \\
\text { mais). Viçosa/MG. }\end{array}$ \\
\hline 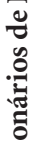 & $\begin{array}{l}\text { Araújo et al., } \\
2008^{18}\end{array}$ & $\begin{array}{l}\text { Desenvolver um QFCA e verificar } \\
\text { a reprodutibilidade para estimar o } \\
\text { consumo alimentar de adolescentes. }\end{array}$ & Semiquantitativo & $\begin{array}{l}430 \text { adolescentes ( } 12 \text { a } 19 \text { anos). } \\
\text { Rio de Janeiro/RJ. }\end{array}$ \\
\hline$\stackrel{\bar{s}}{\tilde{g}}$ & $\begin{array}{l}\text { Fisberg et al., } \\
2008^{19}\end{array}$ & $\begin{array}{l}\text { Desenvolver três QFCA para } \\
\text { mulheres, homens e ambos os } \\
\text { gêneros, com diferentes faixas de } \\
\text { renda. }\end{array}$ & Quantitativo & $\begin{array}{l}1477 \text { indivíduos (20 a } 101 \text { anos). } \\
\text { São Paulo/SP. }\end{array}$ \\
\hline & $\begin{array}{l}\text { Henn et al., } \\
2010^{20}\end{array}$ & $\begin{array}{l}\text { Descrever o desenvolvimento } \\
\text { e validação de um QFCA para } \\
\text { populações de adolescentes, adultos } \\
\text { e idosos. }\end{array}$ & Quantitativo & $\begin{array}{l}268 \text { indivíduos ( } 61 \text { adolescentes, } \\
120 \text { adultos, } 87 \text { idosos). Porto } \\
\text { Alegre/RS. }\end{array}$ \\
\hline & $\begin{array}{l}\text { Ferreira et al., } \\
2010^{21}\end{array}$ & $\begin{array}{l}\text { Descrever a construção de um QFCA } \\
\text { para utilização em estudos que visem } \\
\text { à obtenção de dados sobre o consumo } \\
\text { alimentar de adultos. }\end{array}$ & Semiquantitativo & 104 adultos. Cuiabá/MT. \\
\hline
\end{tabular}




\begin{tabular}{|c|c|c|c|c|}
\hline \multicolumn{5}{|c|}{ Quadro 1. continuação } \\
\hline & Autores, ano & Objetivo do estudo & $\begin{array}{c}\text { Tipo de } \\
\text { questionário }\end{array}$ & $\begin{array}{c}\text { Amostra para elaborar a lista } \\
\text { de alimentos e local } \\
\text { da coleta dos dados }\end{array}$ \\
\hline \multirow{9}{*}{ 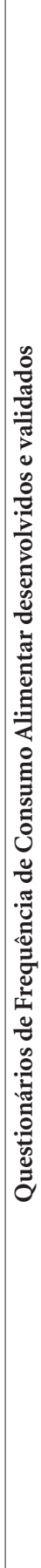 } & $\begin{array}{l}\text { Oliveira et al., } \\
2010^{22}\end{array}$ & $\begin{array}{l}\text { Desenvolver um QFCA para gestantes } \\
\text { adultas usuárias do Sistema Único de } \\
\text { Saúde. }\end{array}$ & Quantitativo & $\begin{array}{l}150 \text { gestantes ( } 18 \text { a } 35 \text { anos). } \\
\text { Ribeirão Preto/SP. }\end{array}$ \\
\hline & $\begin{array}{l}\text { Anjos et al., } \\
2010^{23}\end{array}$ & $\begin{array}{l}\text { Elaborar um QFCA para avaliar a } \\
\text { ingestão de energia e macronutrientes } \\
\text { de adultos. }\end{array}$ & Quantitativo & $\begin{array}{l}1.724 \text { adultos ( } 1.212 \text { mulheres e } \\
512 \text { homens). Niterói/RJ. }\end{array}$ \\
\hline & $\begin{array}{l}\text { Carvalho et al., } \\
2010^{24}\end{array}$ & $\begin{array}{l}\text { Desenvolver e aplicar um QFCA de } \\
\text { autopreenchimento para graduandos } \\
\text { da área de saúde. }\end{array}$ & Quantitativo & $\begin{array}{l}104 \text { universitários de ambos os } \\
\text { sexos. São Paulo/SP. }\end{array}$ \\
\hline & $\begin{array}{l}\text { Scagliusi et al., } \\
2011^{25}\end{array}$ & $\begin{array}{l}\text { Avaliar a validade relativa de um } \\
\text { QFCA desenvolvido para analisar a } \\
\text { ingestão alimentar por escolares da } \\
\text { Amazônia Ocidental. }\end{array}$ & Não informado & $\begin{array}{l}61 \text { crianças ( } 6 \text { a } 9 \text { anos). } \\
\text { Acrelândia/AC. }\end{array}$ \\
\hline & Vian et al., $2013^{26}$ & $\begin{array}{l}\text { Avaliar a reprodutibilidade e validade } \\
\text { de um QFCA destinado à análise } \\
\text { do consumo de alimentos ricos em } \\
\text { polifenóis por gestantes. }\end{array}$ & Quantitativo & 120 gestantes. Porto Alegre/RS. \\
\hline & $\begin{array}{l}\text { Molina et al., } \\
2013^{27}\end{array}$ & $\begin{array}{l}\text { Apresentar o desenvolvimento } \\
\text { do QFCA utilizado no ELSA e as } \\
\text { perspectivas de análise da dieta, como } \\
\text { exposição a doenças cardiovasculares } \\
\text { e diabetes Mellitus tipo } 2 \text {. }\end{array}$ & Semiquantitativo & $\begin{array}{l}\text { Participantes do ELSA nos } \\
\text { últimos } 12 \text { meses, adultos entre } \\
35 \text { e } 74 \text { anos. Seis centros de } \\
\text { investigação: Universidade } \\
\text { Federal da Bahia, Universidade } \\
\text { Federal do Espírito Santo, } \\
\text { Universidade Federal de Minas } \\
\text { Gerais, Universidade de São } \\
\text { Paulo, Fundação Oswaldo Cruz } \\
\text { e Universidade Federal do Rio } \\
\text { Grande do Sul. }\end{array}$ \\
\hline & $\begin{array}{l}\text { Carvalho et al., } \\
2001^{28}\end{array}$ & $\begin{array}{l}\text { Estudar o consumo alimentar de } \\
\text { adolescentes em colégio particular } \\
\text { com a utilização de um QFCA } \\
\text { desenvolvido e avaliar o estado } \\
\text { nutricional. }\end{array}$ & Semiquantitativo & $\begin{array}{l}334 \text { adolescentes ( } 10 \text { a } 19 \text { anos). } \\
\text { Teresina/PI. }\end{array}$ \\
\hline & $\begin{array}{l}\text { Colucci et al., } \\
2004^{29}\end{array}$ & $\begin{array}{l}\text { Desenvolver um QFCA para avaliar } \\
\text { a dieta habitual de crianças de } 2 \text { a } 5 \\
\text { anos. }\end{array}$ & Semiquantitativo & $\begin{array}{l}718 \text { crianças ( } 2 \text { a } 5 \text { anos). São } \\
\text { Paulo/SP. }\end{array}$ \\
\hline & $\begin{array}{l}\text { Furlan-Viebig } \\
\text { e Pastor-Valero, } \\
2004^{30}\end{array}$ & $\begin{array}{l}\text { Desenvolver um QFCA para investigar } \\
\text { possíveis relações entre dieta e } \\
\text { doenças não transmissíveis. }\end{array}$ & Semiquantitativo & 200 adultos. São Paulo/SP. \\
\hline
\end{tabular}




\begin{tabular}{|c|c|c|c|c|}
\hline \multicolumn{5}{|c|}{ Quadro 1. continuação } \\
\hline & Autores, ano & Objetivo do estudo & $\begin{array}{c}\text { Tipo de } \\
\text { questionário }\end{array}$ & $\begin{array}{c}\text { Amostra para elaborar a lista } \\
\text { de alimentos e local } \\
\text { da coleta dos dados }\end{array}$ \\
\hline \multirow{3}{*}{ 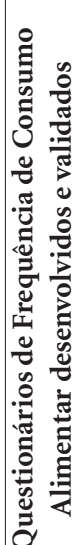 } & $\begin{array}{l}\text { Fornés e } \\
\text { Stringhini, } 2005^{31}\end{array}$ & $\begin{array}{l}\text { Desenvolver um QFCA para } \\
\text { caracterizar o consumo de alimentos } \\
\text { de trabalhadores de baixo nível } \\
\text { socioeconômico. }\end{array}$ & Quantitativo & $\begin{array}{l}104 \text { trabalhadores ( } 15 \text { a } 56 \text { anos). } \\
\text { Goiânia/GO. }\end{array}$ \\
\hline & $\begin{array}{l}\text { Araújo et al., } \\
2010^{32}\end{array}$ & $\begin{array}{l}\text { Descrever a elaboração de um QFCA } \\
\text { para adolescentes. }\end{array}$ & Semiquantitativo & $\begin{array}{l}430 \text { adolescentes ( } 12 \text { a } 18,9 \\
\text { anos). Rio de Janeiro/RJ. }\end{array}$ \\
\hline & $\begin{array}{l}\text { Gonçalves et al., } \\
2011^{33}\end{array}$ & $\begin{array}{l}\text { Descrever o desenvolvimento de um } \\
\text { QFCA para quantificar em massa o } \\
\text { consumo de açúcar em amostra da } \\
\text { população adulta de Porto Alegre, } \\
\text { com base na adaptação de outro } \\
\text { QFCA da mesma população. }\end{array}$ & Quantitativo & $\begin{array}{l}\text { Com base em QFCA direcionado } \\
\text { à população (indicações de seis } \\
\text { nutricionistas conhecedores da } \\
\text { elaboração de QFCA). Porto } \\
\text { Alegre/RS. }\end{array}$ \\
\hline
\end{tabular}

Legenda: QFCA- Questionário de Frequência de Consumo Alimentar; ELSA- Estudo Longitudinal de Saúde do Adulto.

Quadro 2. Características metodológicas do processo de elaboração dos Questionários de Frequência de Consumo Alimentar desenvolvidos no Brasil.

\begin{tabular}{|c|c|c|c|c|c|}
\hline $\begin{array}{l}\text { Autores, } \\
\text { ano }\end{array}$ & $\begin{array}{l}\text { Elaboração da lista de alimentos } \\
\text { e critérios para sua inclusão }\end{array}$ & $\begin{array}{c}\text { Definição do tamanho } \\
\text { das porções }\end{array}$ & $\begin{array}{c}\text { Tempo } \\
\text { pregresso }\end{array}$ & $\begin{array}{c}\text { Categorias para } \\
\text { determinar a frequência } \\
\text { de ingestão }\end{array}$ & $\begin{array}{l}\text { No de itens } \\
\text { alimentares }\end{array}$ \\
\hline $\begin{array}{l}\text { Sichieri e } \\
\text { Everhart, } \\
1998^{10}\end{array}$ & $\begin{array}{l}\text { Baseada nos resultados do } \text { ENDEF }^{34} \text {. } \\
\text { Foram identificados os alimentos } \\
\text { responsáveis por } 86 \% \text { das calorias } \\
\text { totais da população, } 84 \% \text { da ingestão } \\
\text { dietética de vitamina A e } 76 \% \text { da } \\
\text { ingestão dietética de vitamina C. }\end{array}$ & $\begin{array}{l}\text { Porção habitual de cada } \\
\text { item, segundo os resultados } \\
\text { do ENDEF }{ }^{24} \text {, indicando } \\
\text { o tamanho da porção em } \\
\text { diferentes tamanhos para } \\
\text { os alimentos em medidas } \\
\text { caseiras. }\end{array}$ & 12 meses & $\begin{array}{l}\text { Nunca ou quase } \\
\text { nunca, diariamente, } \\
\text { mensalmente, } \\
\text { anualmente. }\end{array}$ & 73 \\
\hline $\begin{array}{l}\text { Cardoso } \\
\text { e Stocco, } \\
2000^{11}\end{array}$ & $\begin{array}{l}\text { Baseada nos resultados de } 3 \text { RA. } \\
\text { Utilizou Block et al. }{ }^{8} \text { como método } \\
\text { para avaliar o teor de nutrientes. } \\
\text { Foram identificados os alimentos } \\
\text { responsáveis por } 90 \% \text { de contribuição } \\
\text { das calorias totais da população. Foram } \\
\text { incluídos ou excluídos da lista outros } \\
\text { itens segundo interesse do autor. }\end{array}$ & $\begin{array}{l}\text { Porção mediana de } \\
\text { referência, estabelecida } \\
\text { segundo o R24h, indicando } \\
\text { o tamanho da porção } \\
\text { (pequeno, médio, grande e } \\
\text { extragrande) em relação à } \\
\text { porção mediana. }\end{array}$ & 12 meses & $\begin{array}{l}\text { Diariamente, } \\
\text { semanalmente, } \\
\text { mensalmente, } \\
\text { anualmente. }\end{array}$ & 230 \\
\hline $\begin{array}{l}\text { Salvo e } \\
\text { Gimeno, } \\
2002^{12}\end{array}$ & $\begin{array}{l}\text { Baseada em levantamento de } \\
\text { prontuários de pessoas obesas. Utilizou } \\
\text { Willett e Lenart }{ }^{7} \text { como método } \\
\text { para estabelecer a porcentagem de } \\
\text { contribuição para valor calórico total } \\
\text { da dieta habitual. Foram identificados } \\
\text { os alimentos ou grupos de alimentos } \\
\text { responsáveis por aproximadamente } \\
90 \% \text { de contribuição das calorias totais } \\
\text { da população. Foram incluídos na lista } \\
\text { outros itens segundo interesse do autor. }\end{array}$ & $\begin{array}{l}\text { Porção mediana dos } \\
\text { alimentos registrados nos } \\
\text { prontuários, usada para } \\
\text { estabelecer os percentis } \\
\text { (menor ou igual a } 25 \text { e } \\
\text { maior que } 75 \text { ), indicando } \\
\text { o tamanho da porção } \\
\text { (pequeno, médio, grande e } \\
\text { extragrande). }\end{array}$ & 1 mês & $\begin{array}{l}\text { Diariamente, } \\
\text { semanalmente, } \\
\text { mensalmente. }\end{array}$ & 90 \\
\hline
\end{tabular}




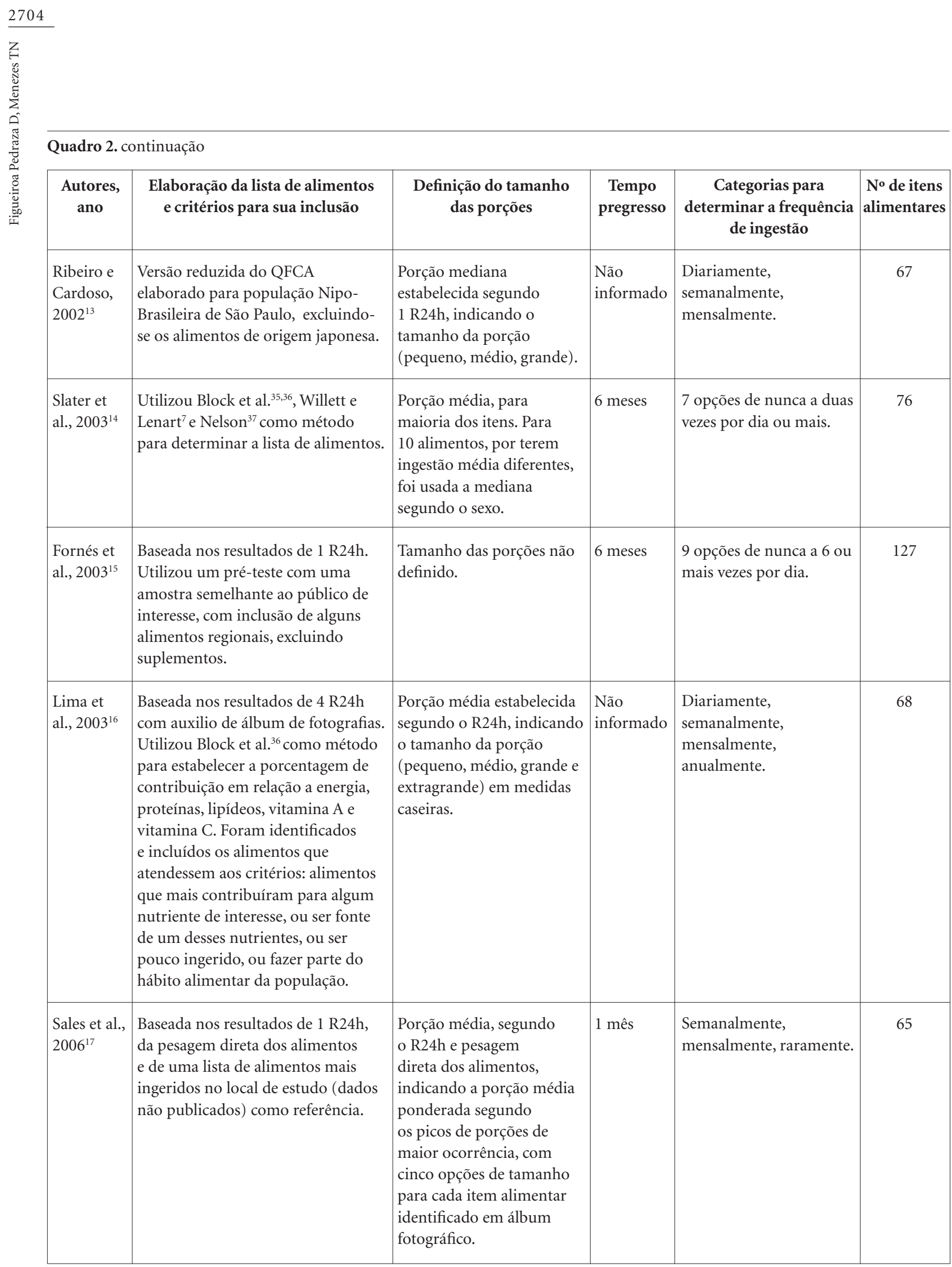


Quadro 2. continuação

\begin{tabular}{|c|c|c|c|c|c|}
\hline $\begin{array}{c}\text { Autores, } \\
\text { ano }\end{array}$ & $\begin{array}{l}\text { Elaboração da lista de alimentos } \\
\text { e critérios para sua inclusão }\end{array}$ & $\begin{array}{l}\text { Definição do tamanho } \\
\text { das porções }\end{array}$ & $\begin{array}{c}\text { Tempo } \\
\text { pregresso }\end{array}$ & $\begin{array}{c}\text { Categorias para } \\
\text { determinar a frequência } \\
\text { de ingestão }\end{array}$ & $\begin{array}{l}\text { No de itens } \\
\text { alimentares }\end{array}$ \\
\hline $\begin{array}{l}\text { Araújo et } \\
\text { al., } 2008^{18}\end{array}$ & $\begin{array}{l}\text { Baseada nos resultados de } 3 \text { RA } \\
\text { não consecutivos. Utilizou Block } \\
\text { et al. }{ }^{8} \text { como método para avaliar a } \\
\text { consistência da lista de alimentos } \\
\text { e confirmar a contribuição de } \\
\text { cada item alimentar incluído no } \\
\text { QFCA. Foram identificados os } \\
\text { alimentos responsáveis por } 95 \% \text { de } \\
\text { contribuição da ingestão total de } \\
\text { energia e de nutrientes avaliados. }\end{array}$ & $\begin{array}{l}\text { Porções típicas ou } \\
\text { naturais e porções modais } \\
\text { (estabelecidas segundo o } \\
\text { R24h), transformando as } \\
\text { informações em medidas } \\
\text { caseiras. }\end{array}$ & 6 meses & 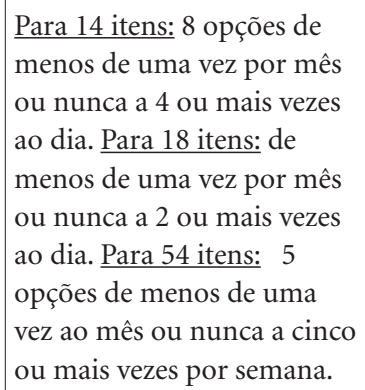 & 86 \\
\hline $\begin{array}{l}\text { Fisberg et } \\
\text { al., } 2008^{19}\end{array}$ & $\begin{array}{l}\text { Baseada nos resultados de } 1 \text { R } 24 \mathrm{~h} . \\
\text { Utilizou Block et al. } .^{35} \text { como método } \\
\text { para determinar a contribuição } \\
\text { percentual dos alimentos. Foram } \\
\text { identificados os alimentos segundo } \\
\text { o ponto de corte de } 90 \% \text { de } \\
\text { contribuição ao total do nutriente. } \\
\text { Foram incluídos na lista outros } \\
\text { itens segundo interesse do autor. }\end{array}$ & $\begin{array}{l}\text { Porção percentilar, } \\
\text { segundo o R24h, indicando } \\
\text { o tamanho da porção } \\
\text { (pequena, média, grande, } \\
\text { extragrande) em medidas } \\
\text { caseiras e gramas. } \\
\end{array}$ & 12 meses & $\begin{array}{l}\text { Diariamente, semanalmente, } \\
\text { mensalmente, anualmente. }\end{array}$ & $\begin{array}{c}\text { Homens e } \\
\text { ambos os } \\
\text { sexos: } 60 \\
\text { Mulheres: } \\
59\end{array}$ \\
\hline $\begin{array}{l}\text { Henn et } \\
\text { al., } 2010^{20}\end{array}$ & $\begin{array}{l}\text { Baseada nos resultados de } 1 \mathrm{R} 24 \mathrm{~h} \text {, } \\
\text { cujos alimentos relatados foram } \\
\text { comparados com um QFCA } \\
\text { realizado no Rio de Janeiro. }\end{array}$ & $\begin{array}{l}\text { Pré-testado em grupos } \\
\text { de pessoas de diferentes } \\
\text { idades e níveis educacionais. } \\
\text { Definido considerando } \\
\text { os tamanhos de álbuns } \\
\text { fotográficos de diferentes } \\
\text { alimentos e medidas caseiras. }\end{array}$ & $\begin{array}{l}\text { Não } \\
\text { informado }\end{array}$ & $\begin{array}{l}\text { Diariamente, semanalmente, } \\
\text { mensalmente, anualmente. }\end{array}$ & 135 \\
\hline $\begin{array}{l}\text { Ferreira } \\
\text { et al., } \\
2010^{21}\end{array}$ & $\begin{array}{l}\text { Baseada nos resultados de } 1 \text { R24h. } \\
\text { Foram identificados os itens } \\
\text { alimentares mais frequentemente } \\
\text { referidos pela amostra avaliada } \\
\text { (mínimo } 15 \% \text { de citação), } \\
\text { considerando tanto o item isolado } \\
\text { quanto como parte de alguma } \\
\text { preparação ou em conjunto com } \\
\text { outros alimentos de composição } \\
\text { nutricional similar. Também } \\
\text { foram incluídos alimentos de } \\
\text { baixo percentual de citação com } \\
\text { capacidade de discriminar o } \\
\text { consumo alimentar ou apontar } \\
\text { tendências de modificação } \\
\text { de hábitos alimentares, } \\
\text { como os alimentos sazonais, } \\
\text { industrializados e preparações } \\
\text { regionais. Utilizou Block et al. } \\
\text { como método para determinar } \\
\text { a contribuição percentual dos } \\
\text { alimentos. Foram identificados os } \\
\text { alimentos responsáveis por } 90 \% \text { de } \\
\text { contribuição da ingestão total de } \\
\text { energia e } 13 \text { nutrientes. }\end{array}$ & $\begin{array}{l}\text { Porções naturais ou } \\
\text { típicas para alimentos que } \\
\text { naturalmente já estão em } \\
\text { porções unitárias. Para } \\
\text { os outros alimentos foi } \\
\text { utilizada, principalmente, } \\
\text { as porçôes alimentares mais } \\
\text { frequentemente relatadas no } \\
\text { R24h. }\end{array}$ & $\begin{array}{l}\text { Não } \\
\text { informado }\end{array}$ & $\begin{array}{l}8 \text { opções de nunca ou quase } \\
\text { nunca a mais de } 3 \text { vezes por } \\
\text { dia. }\end{array}$ & 81 \\
\hline
\end{tabular}




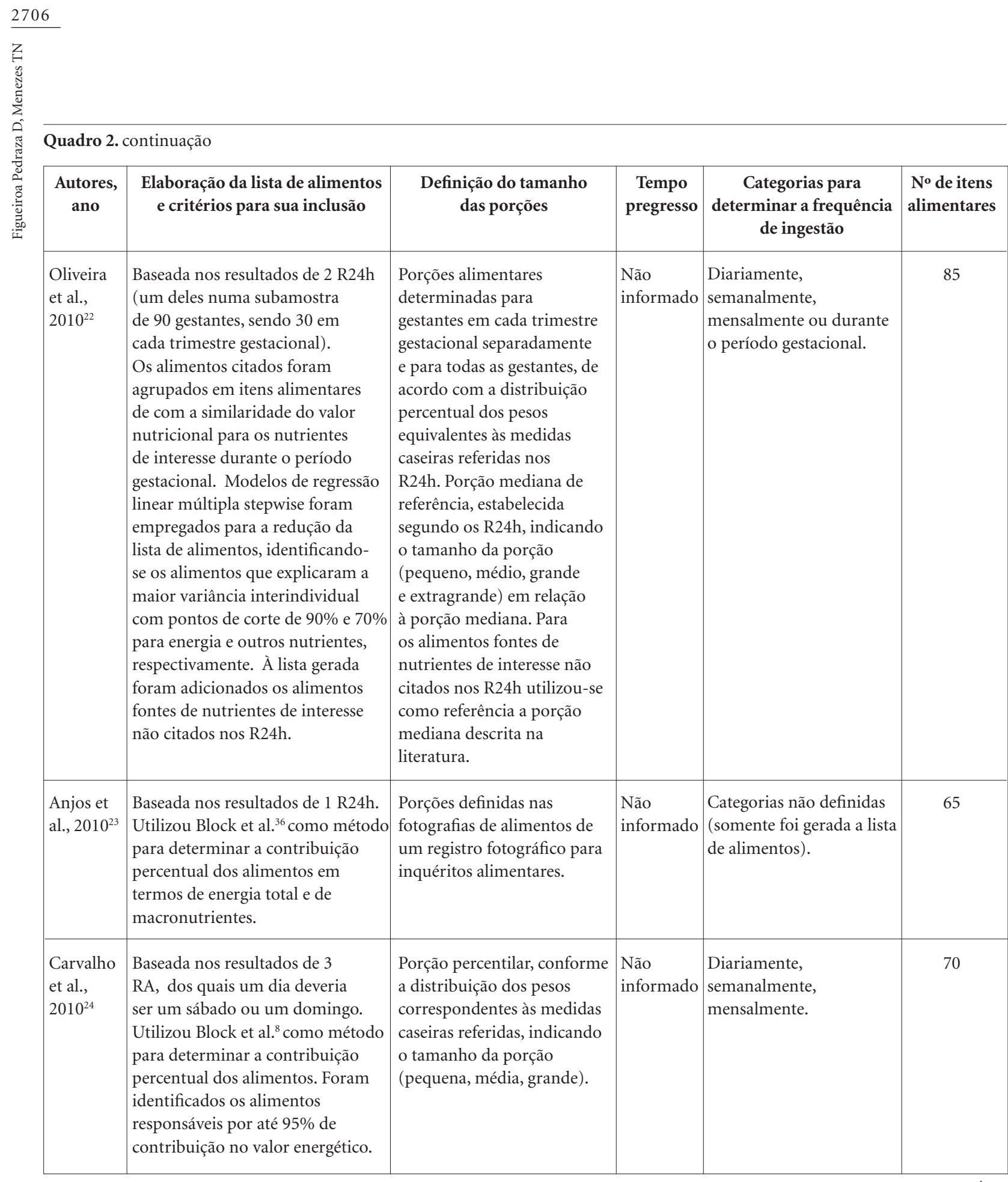

Dos 18 QFCA validados ${ }^{10-27}$ identificados nos estudos, a validação de cinco foi realizada no mesmo estudo no qual foi desenvolvido ${ }^{12,15,20,25,26}$, e a validação dos outros $13^{10,11,13,14,16-19,21-24,27}$, dos quais alguns também foram validados no mesmo estudo ${ }^{10,14}$, foi realizada em 17 estudos diferentes aos do seu desenvolvimento ${ }^{41-57}$, como pode ser observado no Quadro 3, que mostra as características metodológicas do processo de validação. Para a validação, os estudos podem ser discriminados segundo determinadas características da população: adultos ${ }^{10,41,49,52,54,55,57}$, adolescentes $^{14,18,46,47,50}$, gestantes ${ }^{26,42}$, crianças de 5 anos ou mais ${ }^{25,45}$, universitários ${ }^{56}$, mulheres de etnia japonesa ${ }^{43}$, indivíduos de baixa renda ${ }^{15,44}$, situação clínica (excesso de peso, câncer, HPV) $)^{12,48,51}$. 
Quadro 2. continuação

\begin{tabular}{|c|c|c|c|c|c|}
\hline $\begin{array}{l}\text { Autores, } \\
\text { ano }\end{array}$ & $\begin{array}{l}\text { Elaboração da lista de alimentos } \\
\text { e critérios para sua inclusão }\end{array}$ & $\begin{array}{l}\text { Definição do tamanho } \\
\text { das porções }\end{array}$ & $\begin{array}{c}\text { Tempo } \\
\text { pregresso }\end{array}$ & $\begin{array}{c}\text { Categorias para } \\
\text { determinar a frequência } \\
\text { de ingestão }\end{array}$ & $\begin{array}{l}\text { No de itens } \\
\text { alimentares }\end{array}$ \\
\hline $\begin{array}{l}\text { Scagliusi } \\
\text { et al., } \\
2011^{25}\end{array}$ & $\begin{array}{l}\text { Baseada nos resultados de } 1 \text { R24h } \\
\text { e em um QFCA desenvolvido para } \\
\text { uso em adultos, adicionando outros } \\
\text { alimentos que são fonte importante } \\
\text { de outros nutrientes e de consumo } \\
\text { regional. }\end{array}$ & $\begin{array}{l}\text { Tamanho das porções não } \\
\text { definido. }\end{array}$ & $\begin{array}{l}\text { Não } \\
\text { informado }\end{array}$ & $\begin{array}{l}8 \text { opções de nunca ou } \\
\text { quase nunca a todo dia } \\
\text { mais de } 6 \text { vezes por dia. }\end{array}$ & 50 \\
\hline $\begin{array}{l}\text { Vian et } \\
\text { al., } 2013^{26}\end{array}$ & $\begin{array}{l}\text { Baseada na composição dos } \\
\text { alimentos em polifenóis. Utilizou- } \\
\text { se o percentil } 75 \text { como ponto de } \\
\text { corte para discriminar os alimentos } \\
\text { de maior e menor quantidade de } \\
\text { polifenóis. } 44 \text { alimentos foram } \\
\text { selecionados de acordo à American } \\
\text { database }{ }^{38} \text { e oito de acordo ao } \\
\text { estudo de Faller e Fialho }^{39} \text {. }\end{array}$ & $\begin{array}{l}\text { Porção média, estabelecida } \\
\text { segundo QFCA e R24h } \\
\text { usado previamente em } \\
\text { estudo piloto, indicando } \\
\text { o consumo individual em } \\
\text { relação à média (igual, } \\
\text { menor ou maior). }\end{array}$ & $\begin{array}{l}\text { Não } \\
\text { informado }\end{array}$ & $\begin{array}{l}\text { Diariamente, } \\
\text { semanalmente, } \\
\text { mensalmente, } \\
\text { anualmente, raramente. }\end{array}$ & 52 \\
\hline $\begin{array}{l}\text { Molina } \\
\text { et al., } \\
2013^{27}\end{array}$ & $\begin{array}{l}\text { Baseada nos resultados de } 1 \mathrm{R} 24 \mathrm{~h} \\
\text { e em um QFCA previamente } \\
\text { validado, incluindo os itens que } \\
\text { representaram } 86 \% \text { da energia, } \\
84 \% \text { da vitamina A e } 76 \mathrm{da} \\
\text { vitamina C, aos quais foram } \\
\text { adicionados alimentos que refletem } \\
\text { as mudanças dietéticas dos últimos } \\
20 \text { anos e alimentos regionais. }\end{array}$ & $\begin{array}{l}\text { Porção segundo o R24h, } \\
\text { indicando o tamanho usual } \\
\text { das porções em gramas ou } \\
\text { mililitros. }\end{array}$ & 12 meses & $\begin{array}{l}8 \text { opções de nunca/quase } \\
\text { nunca a mais de } 3 \text { vezes } \\
\text { por dia. }\end{array}$ & 114 \\
\hline $\begin{array}{l}\text { Carvalho } \\
\text { et al., } \\
2001^{28}\end{array}$ & $\begin{array}{l}\text { Baseada nos grupos de alimentos } \\
\text { (construtores, reguladores, } \\
\text { energéticos). }\end{array}$ & $\begin{array}{l}\text { Tamanho das porções não } \\
\text { definido. }\end{array}$ & $\begin{array}{l}\text { Última } \\
\text { semana }\end{array}$ & $\begin{array}{l}\text { Menos de uma vez, } 1-2 \\
\text { vezes, } 3-4 \text { vezes, cinco ou } \\
\text { mais vezes. }\end{array}$ & 34 \\
\hline $\begin{array}{l}\text { Colucci et } \\
\text { al., } 2004^{29}\end{array}$ & $\begin{array}{l}\text { Baseada nos resultados de } 1 \text { R } 24 \mathrm{~h} . \\
\text { Utilizou Block et al. }{ }^{35} \text { e Howe et } \\
\text { al. }{ }^{40} \text { como método para determinar } \\
\text { a contribuição percentual dos } \\
\text { alimentos. Foram identificados os } \\
\text { alimentos segundo o ponto de corte } \\
\text { de } 80 \% \text { de contribuição ao total do } \\
\text { nutriente, exceto para vitamina A e } \\
\text { vitamina C que usaram } 55 \% \text { e } 60 \% \text {, } \\
\text { respectivamente. }\end{array}$ & $\begin{array}{l}\text { Porção média e mediana, } \\
\text { estabelecida segundo o R } 24 \mathrm{~h} \text {, } \\
\text { indicando o tamanho das } \\
\text { porções (pequeno, médio, } \\
\text { grande e extragrande) } \\
\text { em medidas caseiras. A } \\
\text { porção mediana foi usada } \\
\text { em apenas } 15 \text { itens que } \\
\text { apresentavam diferenças } \\
\text { na porção de referência } \\
\text { segundo o sexo. }\end{array}$ & 6 meses & $\begin{array}{l}7 \text { opções de nunca a } 2 \text { ou } \\
\text { mais vezes por dia. }\end{array}$ & 57 \\
\hline $\begin{array}{l}\text { Furlan- } \\
\text { Viebig e } \\
\text { Pastor- } \\
\text { Valero, } \\
2004^{30}\end{array}$ & $\begin{array}{l}\text { Baseada nos resultados de } 1 \\
\text { R24h. Utilizou Block et al. } .^{36} \\
\text { como método para determinar } \\
\text { a contribuição percentual dos } \\
\text { alimentos. Foram identificados os } \\
\text { alimentos responsáveis por até } 95 \% \\
\text { da ingestão total de calorias e dos } \\
\text { nutrientes selecionados. }\end{array}$ & $\begin{array}{l}\text { Porção média, estabelecida } \\
\text { segundo o R24h. As porções } \\
\text { foram padronizadas sem } \\
\text { opção de tamanho. }\end{array}$ & $\begin{array}{l}\text { Não } \\
\text { informado } \\
6 \text { meses }\end{array}$ & $\begin{array}{l}9 \text { opções de nunca ou } \\
\text { menos de uma vez ao } \\
\text { mês a acima de } 6 \text { vezes } \\
\text { ao dia. }\end{array}$ & 98 \\
\hline
\end{tabular}




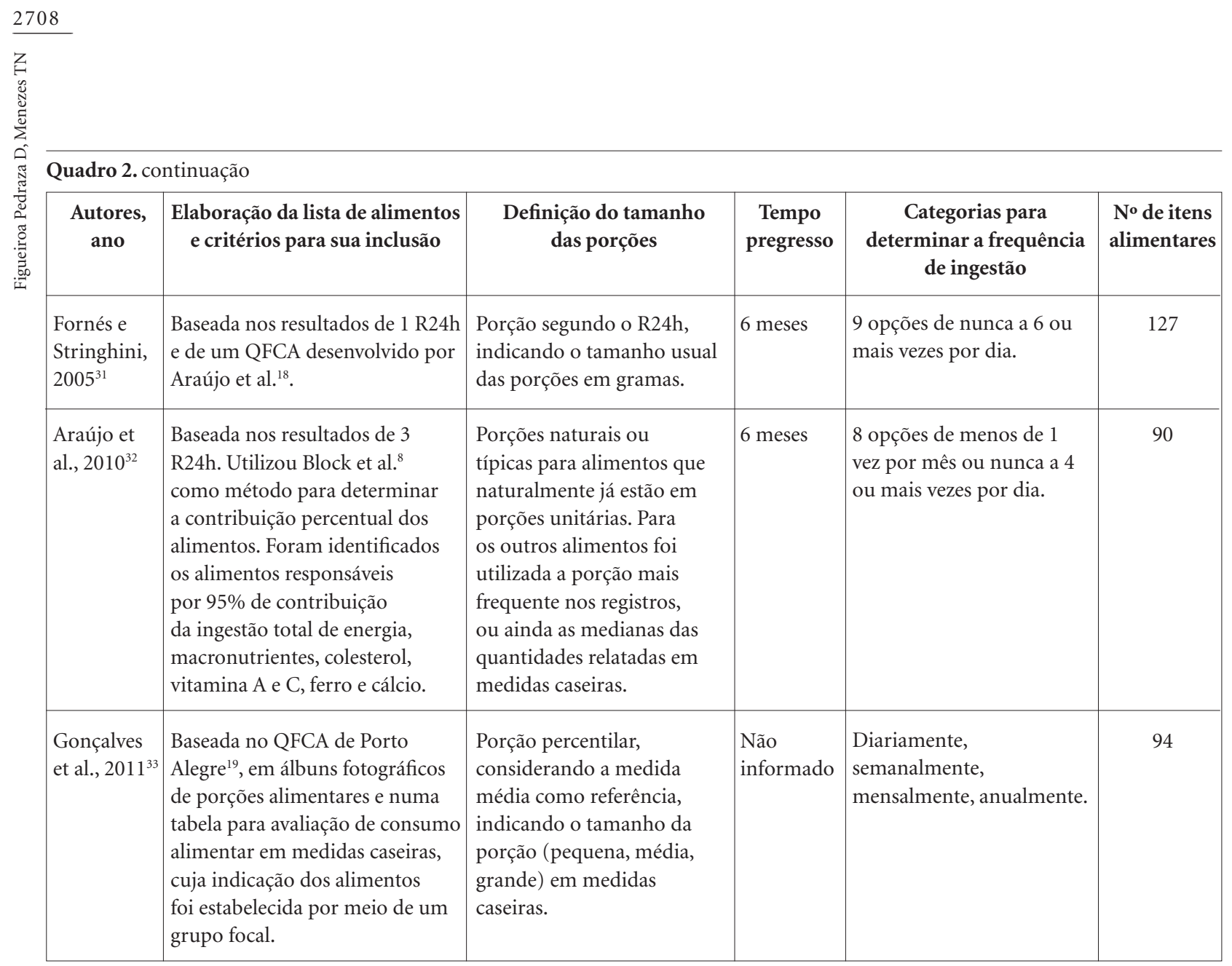

Legenda: QFCA - Questionário de Frequência de Consumo Alimentar; ENDEF - Estudo Nacional de Despesa Familiar; RA - Registro alimentar; R24h Recordatório de 24 horas.

Um dos trabalhos enfocou a validação tanto em adultos quanto em idosos e adolescentes ${ }^{20}$, e três estudos direcionaram as análises a alimentos ou compostos alimentares específicos ${ }^{26,46,47}$. O R24h foi o método de avaliação dietética mais usado como padrão de referência para o estabelecimento de erros sistemáticos na aplicação dos QFCA $^{12,14,15,20,25,26,41,44,46-55}$. A quantidade de R24h empregados variou de dois ${ }^{20,25,26,46,47,52}$ a seis ${ }^{15}$ e o intervalo de aplicação entre os recordatórios variou de 24 horas $^{20}$ a 89 dias $^{41}$. O uso de biomarcadores foi constatado em dois ${ }^{26,47}$ dos estudos revisados, os quais estiveram direcionados à análise do consumo de alimentos ricos em polifenóis ${ }^{26} \mathrm{e}$ da ingestão de carotenóides, frutas e hortaliças ${ }^{47}$.

No Quadro 4 são apresentados os resultados das correlações entre itens analisados nos QFCA e o método de referência. Quatro arti$\operatorname{gos}^{26,46,47,55}$ validaram QFCA para polifenóis ${ }^{26}$; carotenóides, frutas e hortaliças ${ }^{47}$; e por grupos de alimentos ${ }^{46,55}$. Nos demais estudos, os pesquisadores validaram os QFCA utilizando os coe- ficientes de correlação com base nos nutrientes de interesse. Energia ${ }^{10,14,15,20,25,43-45,48-51,53,54,56,57}$, cálcio $^{10,14,15,20,25,41-45,49-52,57}$, fibras ${ }^{14,20,25,41-45,50,51,53,57}$, carboidrato ${ }^{14,20,41,43,44,48,49,51,53,54,57} \mathrm{e}$ vitamina $C^{14,15,20,41-}$ 43,48,49,54,57 foram os itens que mais vezes apresentaram-se classificados como de alta correlação entre o QFCA e o método de referência. Os nutrientes que mais vezes apresentaram-se como de baixa correlação foram: proteína ${ }^{12-15,42,45,48,50-53,56,57}$, lipídeo ${ }^{12,15,20,25,42,45,48-52,56}$, ferro ${ }^{14,15,20,42,44,45,50-53,57}$ e vitamina $\mathrm{A}^{10,14,20,25,41-44,51,53,57}$

Os estudos de validação incluindo população adulta, de ambos os sexos, que apresentaram no QFCA maior número de nutrientes com boa correlação foram os de Molina et al. ${ }^{57}$ (energia, lipídeo, carboidrato, fibras, vitamina $\mathrm{C}$, vitamina $\mathrm{E}$, cálcio, potássio, zinco), Henn et al. ${ }^{20}$ (energia, proteína, fibras, vitamina A, vitamina C, ácido fólico, ferro e cálcio), Zanolla et al. ${ }^{54}$ (energia, proteína, lipídeo, carboidrato, vitamina A, vitamina C, cálcio) e Crispim et al. ${ }^{49}$ (energia, proteína, carboidrato, cálcio, ferro, vitamina A, vitamina C). Para 
Quadro 3. Características metodológicas do processo de validação dos Questionários de Frequência de Consumo Alimentar desenvolvidos e validados no Brasil.

\begin{tabular}{|c|c|c|c|c|c|}
\hline $\begin{array}{l}\text { Autores, ano } \\
\qquad \text { (QFCA } \\
\text { desenvolvidos } \\
\text { de referência) }\end{array}$ & $\begin{array}{l}\text { Autores, ano } \\
\text { (Estudos de } \\
\text { validação) }\end{array}$ & $\begin{array}{l}\text { Objetivo } \\
\text { do estudo }\end{array}$ & $\begin{array}{c}\text { Amostra } \\
\text { utilizada para } \\
\text { validação }\end{array}$ & $\begin{array}{l}\text { Método de } \\
\text { referência e } \\
\text { intervalo } \\
\text { de aplicação }\end{array}$ & $\begin{array}{c}\text { Medidas } \\
\text { de validade }\end{array}$ \\
\hline \multirow[b]{2}{*}{$\begin{array}{l}\text { Sichieri e } \\
\text { Everhart, } \\
1998^{10}\end{array}$} & $\begin{array}{l}\text { Sichieri e } \\
\text { Everhart, } \\
1998^{10}\end{array}$ & $\begin{array}{l}\text { Desenvolver e validar } \\
\text { um QFCA para } \\
\text { trabalhadores adultos. }\end{array}$ & $\begin{array}{l}88 \text { funcionários } \\
\text { de universidade } \\
\text { pública }\end{array}$ & $\begin{array}{l}2 \mathrm{R} 48 \mathrm{~h} \text { com } \\
\text { intervalo de } 15 \\
\text { dias entre os } \\
\text { recordatórios. }\end{array}$ & $\begin{array}{l}\text {-Comparação de médias } \\
\text { (Teste t). } \\
\text {-Análise de correlação } \\
\text { (Coeficiente de correlação } \\
\text { de Pearson). }\end{array}$ \\
\hline & $\begin{array}{l}\text { Ribeiro et al., } \\
2006^{41}\end{array}$ & $\begin{array}{l}\text { Validar e verificar a } \\
\text { reprodutibilidade de um } \\
\text { QFCA para a população } \\
\text { adulta. }\end{array}$ & $\begin{array}{l}69 \text { adultos (média } \\
\text { de } 35,4 \text { anos) }\end{array}$ & $\begin{array}{l}3 \mathrm{R} 24 \mathrm{~h} \text { com } \\
\text { intervalo médio } \\
\text { de } 89 \text { dias entre os } \\
\text { recordatórios. }\end{array}$ & $\begin{array}{l}\text {-Análise de correlação } \\
\text { (Coeficiente de correlação } \\
\text { de Pearson). }\end{array}$ \\
\hline $\begin{array}{l}\text { Cardoso e } \\
\text { Stocco, } 2000^{11}\end{array}$ & $\begin{array}{l}\text { Cardoso et al., } \\
2001^{43}\end{array}$ & $\begin{array}{l}\text { Validar e verificar a } \\
\text { reprodutibilidade de um } \\
\text { QFCA para mulheres de } \\
\text { ascendência japonesa. }\end{array}$ & $\begin{array}{l}52 \text { mulheres } \\
\text { descendentes de } \\
\text { japoneses (média } \\
\text { de } 35 \text { anos) }\end{array}$ & $\begin{array}{l}4 \text { RA de } 3 \text { dias com } \\
\text { intervalo } 90 \text { dias } \\
\text { entre os RA. }\end{array}$ & $\begin{array}{l}\text {-Análise de correlação } \\
\text { (Coeficiente de correlação } \\
\text { de Pearson). }\end{array}$ \\
\hline $\begin{array}{l}\text { Salvo e } \\
\text { Gimeno, } 2002^{12}\end{array}$ & $\begin{array}{l}\text { Salvo e } \\
\text { Gimeno, } 2002^{12}\end{array}$ & $\begin{array}{l}\text { Desenvolver, } \\
\text { validar e verificar a } \\
\text { reprodutibilidade de um } \\
\text { QFCA para população } \\
\text { com excesso de peso. }\end{array}$ & $\begin{array}{l}146 \text { adultos com } \\
\text { excesso de peso }\end{array}$ & $\begin{array}{l}3 \mathrm{R} 24 \mathrm{~h} \text { com } \\
\text { intervalo de } 15 \\
\text { dias entre os } \\
\text { recordatórios. }\end{array}$ & $\begin{array}{l}\text {-Análise de correlação } \\
\text { (Coeficiente de correlação } \\
\text { intraclasse). } \\
\text {-Análise de concordância } \\
\text { (Kappa e Bland-Altman). }\end{array}$ \\
\hline $\begin{array}{l}\text { Ribeiro e } \\
\text { Cardoso, } \\
2002^{13}\end{array}$ & $\begin{array}{l}\text { Monteiro et al., } \\
2008^{45}\end{array}$ & $\begin{array}{l}\text { Verificar a validade } \\
\text { relativa de um QFCA, } \\
\text { previamente validado } \\
\text { em adultos, para } \\
\text { crianças de } 5 \text { a } 10 \text { anos. }\end{array}$ & $\begin{array}{l}152 \text { crianças } \\
\text { saudáveis ( } 5 \text { a } 10 \\
\text { anos) recrutadas } \\
\text { de escolas } \\
\text { públicas }\end{array}$ & 1 R3d. & $\begin{array}{l}\text {-Comparação de médias } \\
\text { (Teste t). } \\
\text {-Análise de correlação } \\
\text { (Coeficiente de correlação } \\
\text { de Pearson). } \\
\text {-Análise de concordância } \\
(\text { Kappa). }\end{array}$ \\
\hline
\end{tabular}

adolescentes, os QFCA validados nos estudos de Henn et al. ${ }^{20}$ (energia, proteína, lipídeo, carboidrato, cálcio, gordura saturada, colesterol, fibras e vitamina C) e de Slater et al. ${ }^{14}$ (energia, lipídeo, carboidrato, cálcio, vitamina C, fibras e colesterol) foram os que apresentaram maior número de nutrientes com boa correlação.

\section{Discussão}

Os resultados do presente estudo mostram que adultos e adolescentes representam os grupos mais contemplados nos estudos de validação de QFCA realizados no Brasil, enquanto estudos específicos para crianças menores de cinco anos 


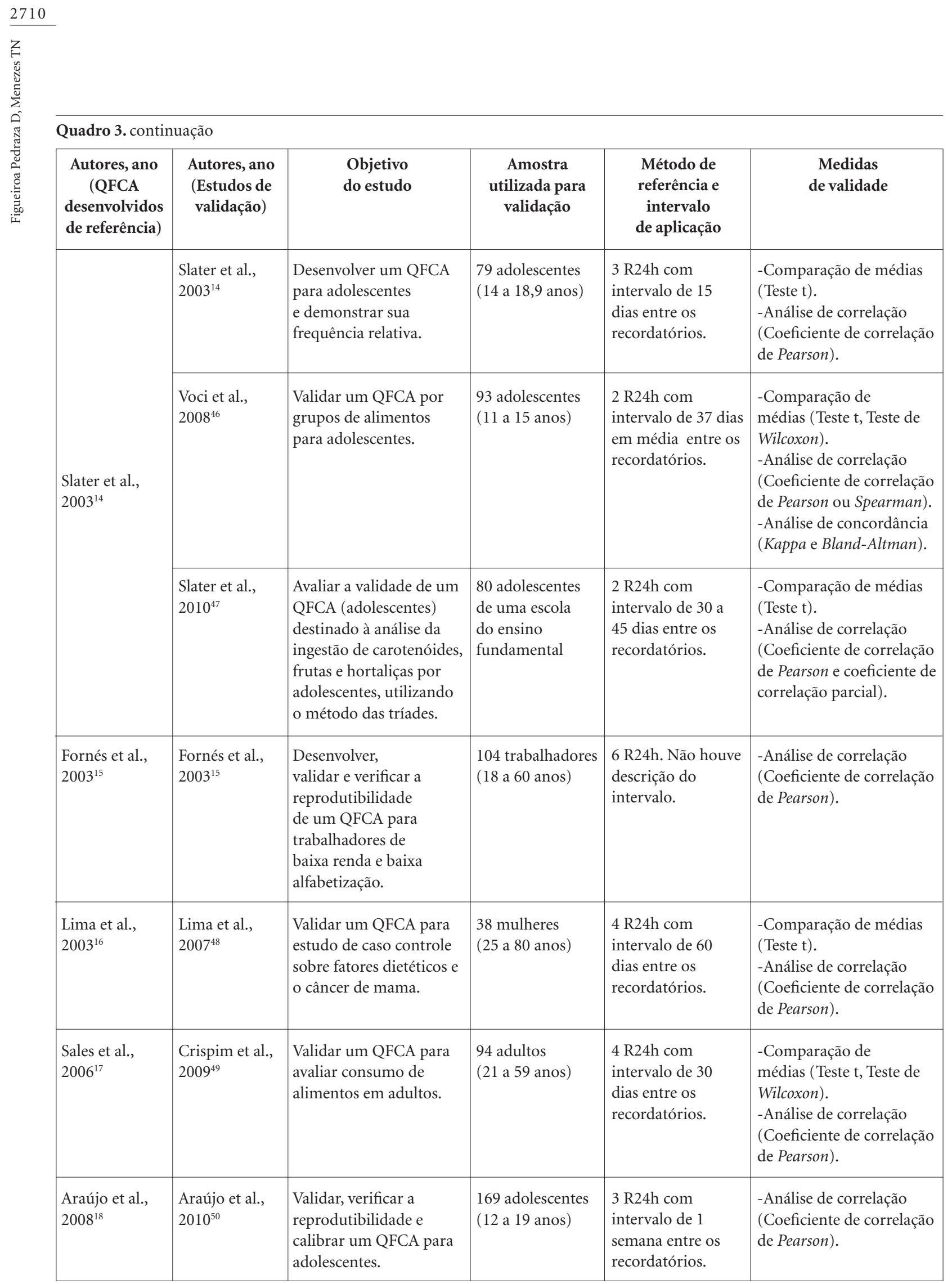




\begin{tabular}{|c|c|c|c|c|c|}
\hline \multicolumn{6}{|c|}{ Quadro 3. continuação } \\
\hline $\begin{array}{l}\text { Autores, ano } \\
\text { (QFCA } \\
\text { desenvolvidos } \\
\text { de referência) }\end{array}$ & $\begin{array}{l}\text { Autores, ano } \\
\text { (Estudos de } \\
\text { validação) }\end{array}$ & $\begin{array}{l}\text { Objetivo } \\
\text { do estudo }\end{array}$ & $\begin{array}{c}\text { Amostra } \\
\text { utilizada para } \\
\text { validação }\end{array}$ & $\begin{array}{l}\text { Método de } \\
\text { referência e } \\
\text { intervalo } \\
\text { de aplicação }\end{array}$ & $\begin{array}{c}\text { Medidas } \\
\text { de validade }\end{array}$ \\
\hline $\begin{array}{l}\text { Fisberg et al., } \\
2008^{19}\end{array}$ & $\begin{array}{l}\text { Teixeira et al., } \\
2011^{51}\end{array}$ & $\begin{array}{l}\text { Validar e verificar a } \\
\text { reprodutibilidade } \\
\text { de um QFCA para } \\
\text { avaliar a ingestão } \\
\text { dietética de energia e } 19 \\
\text { nutrientes em homens } \\
\text { participantes do estudo } \\
\text { HIM (Natural History of } \\
\text { HPV Infection in Men) } \\
\text { em São Paulo. }\end{array}$ & $\begin{array}{l}98 \text { homens } \\
(18 \text { a } 70 \text { anos })\end{array}$ & $\begin{array}{l}3 \mathrm{R} 24 \mathrm{~h} \text { com } \\
\text { intervalo de seis } \\
\text { meses entre os } \\
\text { recordatórios. }\end{array}$ & $\begin{array}{l}\text {-Comparação de médias } \\
\text { (Teste t, Teste de Wilcoxon, } \\
\text { Teste de Mann-Whitney). } \\
\text {-Análise de correlação } \\
\text { (Coeficiente de correlação } \\
\text { de Pearson ou Spearman). } \\
\text {-Análise de concordância } \\
\text { (Kappa e Bland-Altman). }\end{array}$ \\
\hline $\begin{array}{l}\text { Henn et al., } \\
2010^{20}\end{array}$ & $\begin{array}{l}\text { Henn et al., } \\
2010^{20}\end{array}$ & $\begin{array}{l}\text { Descrever o } \\
\text { desenvolvimento e } \\
\text { validação de um QFCA } \\
\text { para populações de } \\
\text { adolescentes, adultos e } \\
\text { idosos. }\end{array}$ & $\begin{array}{l}125 \text { adolescentes, } \\
66 \text { adultos e } 47 \\
\text { idosos }\end{array}$ & $\begin{array}{l}2 \mathrm{R} 24 \mathrm{~h} \text { em } \\
\text { dois períodos } \\
\text { consecutivos de } 24 \\
\text { horas. }\end{array}$ & $\begin{array}{l}\text {-Comparação de médias } \\
\text { (Teste t) } \\
\text {-Análise de correlação } \\
\text { (Coeficiente de correlação } \\
\text { de Pearson). }\end{array}$ \\
\hline $\begin{array}{l}\text { Ferreira et al., } \\
2010^{21}\end{array}$ & $\begin{array}{l}\text { Silva et al., } \\
2013^{52}\end{array}$ & $\begin{array}{l}\text { Avaliar a } \\
\text { reprodutibilidade e a } \\
\text { validade relativa de um } \\
\text { QFCA e estimar seus } \\
\text { fatores de calibração. }\end{array}$ & $\begin{array}{l}195 \text { adultos } \\
\text { (20 a } 50 \text { anos) }\end{array}$ & $\begin{array}{l}2 \text { R } 24 \mathrm{~h} \text { com } \\
\text { intervalo de } 30 \\
\text { dias. }\end{array}$ & $\begin{array}{l}\text { - Comparação de médias } \\
\text { (Teste t). } \\
\text {-Análise de correlação } \\
\text { (Coeficiente de correlação } \\
\text { de Pearson). }\end{array}$ \\
\hline $\begin{array}{l}\text { Oliveira et al., } \\
2010^{22}\end{array}$ & $\begin{array}{l}\text { Barbieri et al., } \\
2012^{53}\end{array}$ & $\begin{array}{l}\text { Avaliar a validade de um } \\
\text { QFCA, desenvolvido } \\
\text { para o seu uso em } \\
\text { adolescentes, para } \\
\text { estimar a ingestão de } \\
\text { nutrientes durante a } \\
\text { gravidez. }\end{array}$ & $\begin{array}{l}103 \text { gestantes } \\
(18 \text { a } 35 \text { anos })\end{array}$ & $\begin{array}{l}3 \text { R24h, um por } \\
\text { trimestre da } \\
\text { gestação. }\end{array}$ & $\begin{array}{l}\text {-Análise de correlação } \\
\text { (Coeficiente de correlação } \\
\text { de Pearson). } \\
\text {-Análise de concordância } \\
(\text { Kappa). }\end{array}$ \\
\hline \multirow[t]{2}{*}{$\begin{array}{l}\text { Anjos et al., } \\
2010^{23}\end{array}$} & $\begin{array}{l}\text { Zanolla et al., } \\
2009^{54}\end{array}$ & $\begin{array}{l}\text { Avaliar a } \\
\text { reprodutibilidade e a } \\
\text { validade relativa de um } \\
\text { QFCA. }\end{array}$ & 83 adultos & $\begin{array}{l}3 \text { R24h com } \\
\text { intervalo médio de } \\
14 \text { dias. }\end{array}$ & $\begin{array}{l}\text { - Comparação de médias } \\
\text { (Teste t). } \\
\text { - Análise de correlação } \\
\text { (Coeficiente de correlação } \\
\text { intraclasse) }\end{array}$ \\
\hline & $\begin{array}{l}\text { Machado et al., } \\
2012^{55}\end{array}$ & $\begin{array}{l}\text { Testar a } \\
\text { reprodutibilidade e } \\
\text { validade de um QFCA. }\end{array}$ & $\begin{array}{l}128 \text { adultos ( } 20 \mathrm{a} \\
69 \text { anos) }\end{array}$ & $\begin{array}{l}3 \text { R } 24 \mathrm{~h} \text { com } \\
\text { intervalo médio de } \\
16 \text { dias. }\end{array}$ & $\begin{array}{l}\text {-Análise de correlação } \\
\text { (Coeficiente de correlação } \\
\text { de Spearman). }\end{array}$ \\
\hline $\begin{array}{l}\text { Carvalho et al., } \\
2010^{24}\end{array}$ & $\begin{array}{l}\text { Komatsu et al., } \\
2013^{56}\end{array}$ & $\begin{array}{l}\text { Validar um QFCA em } \\
\text { graduandos da área de } \\
\text { saúde. }\end{array}$ & 50 universitários & $\begin{array}{l}3 \text { RA em um } \\
\text { período de } 6 \text { meses. }\end{array}$ & $\begin{array}{l}\text { - Comparação de médias } \\
\text { (Teste t). } \\
\text { - Análise de correlação } \\
\text { (Coeficiente de correlação } \\
\text { intraclasse) }\end{array}$ \\
\hline
\end{tabular}




\begin{tabular}{|c|c|c|c|c|c|c|}
\hline \multirow{5}{*}{ 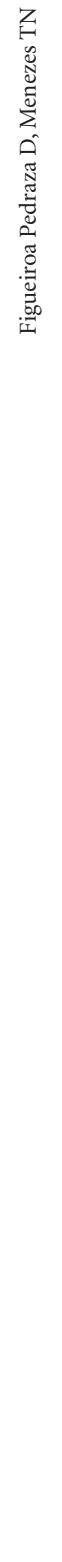 } & Quadro 3. contir & uação & & & & \\
\hline & $\begin{array}{l}\text { Autores, ano } \\
\text { (QFCA } \\
\text { desenvolvidos } \\
\text { de referência) }\end{array}$ & $\begin{array}{l}\text { Autores, ano } \\
\text { (Estudos de } \\
\text { validação) }\end{array}$ & $\begin{array}{c}\text { Objetivo } \\
\text { do estudo }\end{array}$ & $\begin{array}{l}\text { Amostra } \\
\text { utilizada para } \\
\text { validação }\end{array}$ & $\begin{array}{l}\text { Método de } \\
\text { referência e } \\
\text { intervalo } \\
\text { de aplicação }\end{array}$ & $\begin{array}{l}\text { Medidas } \\
\text { de validade }\end{array}$ \\
\hline & $\begin{array}{l}\text { Scagliusi et al., } \\
2011^{25}\end{array}$ & $\begin{array}{l}\text { Scagliusi et al., } \\
2011^{25}\end{array}$ & $\begin{array}{l}\text { Avaliar a validade } \\
\text { relativa de um QFCA } \\
\text { desenvolvido para } \\
\text { analisar a ingestão } \\
\text { alimentar por escolares } \\
\text { da Amazônia Ocidental. }\end{array}$ & $\begin{array}{l}61 \text { crianças } \\
\text { (6 a } 9 \text { anos) }\end{array}$ & $\begin{array}{l}2 \text { R24h com } \\
\text { intervalo médio de } \\
1 \text { mês. }\end{array}$ & $\begin{array}{l}\text {-Comparação de médias } \\
\text { (Teste t). } \\
\text {-Análise de correlação } \\
\text { (Coeficiente de correlação } \\
\text { de Pearson). } \\
\text {-Análise de concordância } \\
\text { (Bland-Altman). }\end{array}$ \\
\hline & $\begin{array}{l}\text { Vian et al., } \\
2013^{26}\end{array}$ & $\begin{array}{l}\text { Vian et al., } \\
2013^{26}\end{array}$ & $\begin{array}{l}\text { Avaliar a } \\
\text { reprodutibilidade e } \\
\text { validade de um QFCA } \\
\text { destinado à análise do } \\
\text { consumo de alimentos } \\
\text { ricos em polifenóis por } \\
\text { gestantes. }\end{array}$ & $\begin{array}{l}120 \text { gestantes } \\
\text { (93 completaram } \\
\text { todos os métodos } \\
\text { de estudo) }\end{array}$ & $\begin{array}{l}2 \mathrm{R} 24 \mathrm{~h}, 1 \mathrm{R} 3 \mathrm{~d} \text { e } \\
\text { excreção urinária } \\
\text { de polifenóis. } \\
\text { Os dados foram } \\
\text { coletados em dois } \\
\text { momentos com } \\
\text { intervalo de } 15 \\
\text { dias. No primeiro } \\
\text { momento, usou- } \\
\text { se o QFCA e o } \\
\text { R24h. No segundo } \\
\text { momento, usou-se } \\
\text { o QFCA e o R3d. }\end{array}$ & $\begin{array}{l}\text {-Comparação de médias } \\
\text { (Teste t). } \\
\text {-Análise de correlação } \\
\text { (Coeficiente de correlação } \\
\text { de Pearson). } \\
\text {-Análise de concordância } \\
\text { (Kappa e Bland-Altman). }\end{array}$ \\
\hline & $\begin{array}{l}\text { Molina et al., } \\
2013^{27}\end{array}$ & $\begin{array}{l}\text { Molina et al., } \\
2013^{57}\end{array}$ & $\begin{array}{l}\text { Avaliar a confiabilidade } \\
\text { e a validade relativa } \\
\text { do QFCA utilizado no } \\
\text { ELSA. }\end{array}$ & $\begin{array}{l}381 \text { adultos } \\
\text { (35 a } 74 \text { anos) }\end{array}$ & $\begin{array}{l}3 \text { RA em } \\
\text { momentos } \\
\text { distintos no } \\
\text { intervalo } \\
\text { compreendido } \\
\text { entre aplicação de } \\
2 \text { QFCA, no } \\
\text { período de um ano. }\end{array}$ & $\begin{array}{l}\text {-Comparação de médias } \\
\text { (Teste t). } \\
\text {-Análise de correlação } \\
\text { (Coeficiente de correlação } \\
\text { intraclasse). } \\
\text {-Análise de concordância } \\
\text { (Bland-Altman). } \\
\text {-Análise de dispersão } \\
\text { (Beanplot). }\end{array}$ \\
\hline
\end{tabular}

Legenda: QFCA- Questionário de Frequência de Consumo Alimentar; RA - Registro Alimentar; R24h- Recordatório de 24 horas; R48h- Recordatório de 48 horas; R3d- Recordatório de três dias; ELSA- Estudo Longitudinal de Saúde do Adulto.

não foram encontrados. Isso poderá dificultar que outros pesquisadores desenvolvam trabalhos sobre frequência alimentar e saúde nesse grupo populacional, a não ser que os mesmos se proponham a desenvolvê-los e validá-los.

Considerando os resultados encontrados, a validação do QFCA desenvolvido no estudo de Colucci et al. ${ }^{29}$ seria uma alternativa para analisar como a dieta habitual de crianças menores de cinco anos se relaciona com o desenvolvimento de doenças. Estudos com crianças têm sido desenvolvidos em outros países, como é o caso do que objetivou a validação de um QFCA em crianças coreanas $^{58}$. A avaliação da ingestão dietética em crianças, quando as mesmas participam como respondentes, apresenta dificuldades atreladas à habilidade das mesmas para reportar e cooperar com os procedimentos, o que pode explicar limitações relacionadas à realização de estudos com esse grupo etário ${ }^{3}$.

A validação específica para idosos foi contemplada em um único estudo ${ }^{20}$. A carência de instrumentos direcionados especificamente para avaliar a ingestão alimentar de idosos pode estar relacionada com as limitações próprias do método, como dependência da memória, complexi- 
Quadro 4. Correlação entre os itens analisados nos Questionários de Frequência de Consumo Alimentar validados no Brasil e o método de referência.

\begin{tabular}{|c|c|c|c|}
\hline $\begin{array}{l}\text { Autores, } \\
\text { ano }\end{array}$ & $\begin{array}{l}\text { Itens com alta correlação } \\
\qquad(\mathbf{r} \geq \mathbf{0 , 4 )}\end{array}$ & $\begin{array}{l}\text { Itens com baixa correlação } \\
\qquad(\mathrm{r}<\mathbf{0 , 4 )}\end{array}$ & Observações \\
\hline $\begin{array}{l}\text { Sichieri e } \\
\text { Everhart, } \\
1998^{10}\end{array}$ & $\begin{array}{l}\text { Energia; Proteína; Lipídeo; Ferro; } \\
\text { Cálcio. }\end{array}$ & $\begin{array}{l}\text { Carboidrato; Vitamina A; } \\
\text { Vitamina C. }\end{array}$ & $\begin{array}{l}\text { Mulheres com excesso de peso } \\
\text { subestimaram sua ingestão em relação } \\
\text { a mulheres eutróficas. }\end{array}$ \\
\hline $\begin{array}{l}\text { Ribeiro et } \\
\text { al., } 2006^{41}\end{array}$ & $\begin{array}{l}\text { Proteína; Lipídeo; Carboidrato; } \\
\text { Vitamina C; Ferro; Cálcio; Zinco; } \\
\text { Fibras. }\end{array}$ & Colesterol; Vitamina A. & $\begin{array}{l}\text { QFCA considerado bom, com } \\
\text { coeficientes de correlação expressivos } \\
\text { para alguns nutrientes, mas, } \\
\text { indicando-se a necessidade de } \\
\text { modificações. }\end{array}$ \\
\hline $\begin{array}{l}\text { Giacomello } \\
\text { et al., } 2008^{42}\end{array}$ & $\begin{array}{l}\text { Fibras; Vitamina C; Ácido Fólico; } \\
\text { Cálcio; Potássio. }\end{array}$ & $\begin{array}{l}\text { Energia; Proteína; Lipídeo; } \\
\text { Carboidrato; Colesterol; Vitamina } \\
\text { A; Tiamina; Riboflavina; } \\
\text { Piridoxina; Cianocobalamina; } \\
\text { Vitamina E; Niacina; Ácido } \\
\text { Pantotênico; Sódio; Magnésio; } \\
\text { Zinco; Fósforo; Ferro; Cobre; } \\
\text { Selênio. }\end{array}$ & $\begin{array}{l}\text { Em geral, o QFCA superestimou a } \\
\text { ingestão de energia e nutrientes. }\end{array}$ \\
\hline $\begin{array}{l}\text { Cardoso et } \\
\text { al., } 2001^{43}\end{array}$ & $\begin{array}{l}\text { Energia; Proteína; Lipídeo; } \\
\text { Carboidrato; Colesterol; Fibras; } \\
\text { Vitamina C; Ácido Fólico; Tiamina; } \\
\text { Niacina; Piridoxina; Cálcio; Potássio; } \\
\text { Ferro; Fósforo. }\end{array}$ & $\begin{array}{l}\text { Vitamina A; Vitamina E; } \\
\text { Riboflavina; Sódio }\end{array}$ & $\begin{array}{l}\text { QFCA direcionado a grupo específico, } \\
\text { indicando-se a necessidade de novos } \\
\text { estudos em outras populações. }\end{array}$ \\
\hline $\begin{array}{l}\text { Cardoso et } \\
\text { al., } 2010^{44}\end{array}$ & $\begin{array}{l}\text { Energia; Lipídeo; Carboidrato; } \\
\text { Colesterol; Fibras; Ácido Fólico; } \\
\text { Riboflavina; Cálcio. }\end{array}$ & $\begin{array}{l}\text { Vitamina A; Vitamina E; } \\
\text { Vitamina C; Tiamina; Piridoxina; } \\
\text { Cianocobalamina; Niacina; } \\
\text { Magnésio; Zinco; Ferro. }\end{array}$ & $\begin{array}{l}\text { Os gráficos de Bland-Altman } \\
\text { apontaram que o QFCA é preciso na } \\
\text { avaliação da ingestão de nutrientes em } \\
\text { nível de grupo. }\end{array}$ \\
\hline $\begin{array}{l}\text { Salvo e } \\
\text { Gimeno, } \\
2002^{12}\end{array}$ & - & $\begin{array}{l}\text { Energia; Proteína; Lipídeo; } \\
\text { Carboidrato. }\end{array}$ & $\begin{array}{l}\text { Maior variabilidade de alimentos } \\
\text { entre pessoas obesas do que nas } \\
\text { pessoas com excesso de peso. } \\
\text { Indivíduos com excesso de peso } \\
\text { subestimaram a ingestão de alimentos. }\end{array}$ \\
\hline $\begin{array}{l}\text { Monteiro et } \\
\text { al., } 2008^{45}\end{array}$ & $\begin{array}{l}\text { Energia; Fibras; Vitamina C; Ácido } \\
\text { Fólico; Vitamina A; Vitamina E; } \\
\text { Riboflavina; Cálcio; Potássio. }\end{array}$ & $\begin{array}{l}\text { Proteína; Lipídeo; Carboidrato; } \\
\text { Gordura Saturada; Colesterol; } \\
\text { Piridoxina; Sódio; Zinco; Ferro. }\end{array}$ & $\begin{array}{l}\text { Em geral, o QFCA superestimou a } \\
\text { ingestão de energia e nutrientes. }\end{array}$ \\
\hline $\begin{array}{l}\text { Slater et al., } \\
2003^{14}\end{array}$ & $\begin{array}{l}\text { Energia; Lipídeo; Carboidrato; } \\
\text { Colesterol; Fibras; Vitamina C; Cálcio. }\end{array}$ & Proteína; Vitamina A; Ferro. & $\begin{array}{l}\text { Os autores utilizaram coeficiente de } \\
\text { correlação ajustada pela energia e } \\
\text { pela variância intrapessoal, segundo } \\
\text { sexo. Após ajuste, os coeficientes de } \\
\text { correlação tenderam a diminuir. }\end{array}$ \\
\hline $\begin{array}{l}\text { Voci et al., } \\
2008^{46}\end{array}$ & $\begin{array}{l}\text { Salgados; Leite e derivados; Gorduras; } \\
\text { Biscoitos recheados; Arroz; Verduras e } \\
\text { legumes; Frutas; Feijão; Refrigerantes } \\
\text { com açúcar; Sucos artificiais e } \\
\text { infusões; Sucos naturais. }\end{array}$ & $\begin{array}{l}\text { Salgadinhos; Doces; Massas; } \\
\text { Óleos. }\end{array}$ & $\begin{array}{l}\text { QFCA superestimou todos os } \\
\text { grupos, exceto óleos, feijão, carnes e } \\
\text { refrigerantes que foram subestimados. } \\
\text { Não foi possível corrigir os coeficientes } \\
\text { de correlação de pães e carnes pela } \\
\text { elevada variância intrapessoal. }\end{array}$ \\
\hline
\end{tabular}




\begin{tabular}{|c|c|c|c|}
\hline \multicolumn{4}{|l|}{2714} \\
\hline \multicolumn{4}{|c|}{ 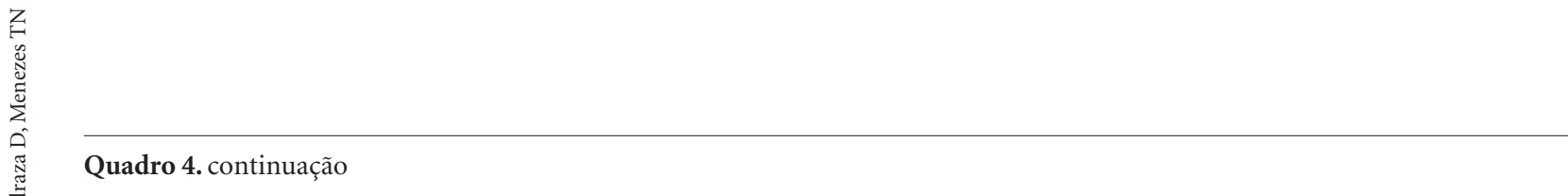 } \\
\hline $\begin{array}{l}\text { Autores, } \\
\text { ano }\end{array}$ & $\begin{array}{l}\text { Itens com alta correlação } \\
\qquad(\mathrm{r} \geq \mathbf{0 , 4 )}\end{array}$ & $\begin{array}{l}\text { Itens com baixa correlação } \\
\qquad(\mathrm{r}<\mathbf{0 , 4 )}\end{array}$ & Observações \\
\hline $\begin{array}{l}\text { Slater et al., } \\
2010^{47}\end{array}$ & $\begin{array}{l}\text { Carotenóides, Frutas, Vegetais, Frutas/ } \\
\text { Vegetais. }\end{array}$ & - & $\begin{array}{l}\text { Maiores coeficientes de validade para } \\
\text { frutas, vegetais e frutas/vegetais do } \\
\text { QFCA do que os valores obtidos a } \\
\text { partir do R24h e dos níveis séricos de } \\
\beta \text {-caroteno. }\end{array}$ \\
\hline $\begin{array}{l}\text { Fornés et } \\
\text { al., } 2003^{15}\end{array}$ & $\begin{array}{l}\text { Energia; Vitamina C; Vitamina A; } \\
\text { Cálcio. }\end{array}$ & $\begin{array}{l}\text { Proteína; Lipídeo; Carboidrato; } \\
\text { Ferro. }\end{array}$ & $\begin{array}{l}\text { Os autores validaram o QFCA em dois } \\
\text { momentos diferentes. }\end{array}$ \\
\hline $\begin{array}{l}\text { Lima et al., } \\
2007^{48}\end{array}$ & $\begin{array}{l}\text { Energia; Carboidrato. Vitamina A; } \\
\text { Vitamina C. }\end{array}$ & Proteína; Lipídeo. & $\begin{array}{l}\text { Após o ajuste pela variabilidade } \\
\text { intrapessoal, os coeficientes de } \\
\text { correlação aumentaram para vitamina } \\
\text { A, vitamina C e carboidratos. }\end{array}$ \\
\hline $\begin{array}{l}\text { Crispim et } \\
\text { al., } 2009^{49}\end{array}$ & $\begin{array}{l}\text { Energia; Proteína; Carboidrato; } \\
\text { Vitamina A; Vitamina C; Ferro; } \\
\text { Cálcio. }\end{array}$ & Lipídeo. & $\begin{array}{l}\text { Os autores utilizaram coeficiente de } \\
\text { correlação ajustada pela energia e pela } \\
\text { variância intrapessoal, segundo sexo, } \\
\text { encontrando uma concordância não } \\
\text { perfeita, mais aceitável entre os dois } \\
\text { métodos. QFCA subestimou vitamina } \\
\text { C, vitamina A e cálcio. }\end{array}$ \\
\hline $\begin{array}{l}\text { Araújo et } \\
\text { al., } 2010^{50}\end{array}$ & Energia; Cálcio; Fibras. & $\begin{array}{l}\text { Proteína; Lipídeo; Carboidrato; } \\
\text { Ferro; Fósforo. }\end{array}$ & $\begin{array}{l}\text { Após ajuste pela energia, os } \\
\text { coeficientes de correlação de todos os } \\
\text { nutrientes diminuíram os valores de } \\
\text { correlação, exceto cálcio e fibra. }\end{array}$ \\
\hline $\begin{array}{l}\text { Teixeira et } \\
\text { al., } 2011^{51}\end{array}$ & $\begin{array}{l}\text { Energia; Carboidrato; Fibras; Ácido } \\
\text { Fólico; Tiamina; Cálcio. }\end{array}$ & $\begin{array}{l}\text { Proteína; Lipídeo; Gordura } \\
\text { Saturada; Gordura } \\
\text { Monoinsaturada; Gordura } \\
\text { Poliinsaturada; Gordura } \\
\text { Trans; Colesterol; Vitamina A; } \\
\text { Vitamina C; Vitamina E; Niacina; } \\
\text { Riboflavina; Fósforo; Ferro. }\end{array}$ & $\begin{array}{l}\text { As diferenças encontradas dependeram } \\
\text { da magnitude da ingestão, tanto } \\
\text { para energia quanto para nutrientes, } \\
\text { exceto carboidratos, fibra, gordura } \\
\text { poliinsaturada, vitamina C e vitamina } \\
\text { E. }\end{array}$ \\
\hline $\begin{array}{l}\text { Henn et al., } \\
2010^{20}\end{array}$ & $\begin{array}{l}\text { Adolescentes } \\
\text { Energia; Proteína; Fibras; Vitamina } \\
\text { A; Vitamina C; Ácido Fólico; Ferro; } \\
\text { Cálcio. } \\
\underline{\text { Adultos }} \\
\text { Energia; Proteína; Lipídeo; } \\
\text { Carboidrato; Gordura Saturada; } \\
\text { Colesterol; Fibras; Vitamina C; Cálcio. } \\
\underline{\text { Idosos }} \text { Energia; Proteína; Lipídeo; } \\
\text { Carboidrato; Gordura Saturada; } \\
\text { Colesterol; Fibras; Vitamina A; } \\
\text { Vitamina C; Cálcio; Zinco. }\end{array}$ & $\begin{array}{l}\text { Adolescentes } \\
\text { Lipídeo; Carboidrato; Gordura } \\
\text { saturada; Colesterol; Vitamina E; } \\
\text { Zinco. } \\
\underline{\text { Adultos }} \\
\text { Vitamina A; Vitamina E; Ácido } \\
\text { Fólico; Zinco; Ferro. } \\
\underline{\text { Idosos }} \\
\text { Vitamina E; Ácido Fólico; Ferro. }\end{array}$ & $\begin{array}{l}\text { QFCA considerado útil para estudar } \\
\text { os determinantes alimentares de } \\
\text { obesidade e de doenças crônicas não } \\
\text { transmissíveis. }\end{array}$ \\
\hline $\begin{array}{l}\text { Silva et al., } \\
2013^{52}\end{array}$ & Cálcio. & $\begin{array}{l}\text { Proteína; Lipídeo; Carboidrato; } \\
\text { Gordura Saturada; Gordura } \\
\text { Insaturada; Colesterol; Fibras; } \\
\text { Vitamina C; Tiamina; Ácido } \\
\text { Fólico; Ferro. }\end{array}$ & $\begin{array}{l}\text { A deatenuação associada ao ajuste } \\
\text { para a energia reduziu a maioria dos } \\
\text { coeficientes de correlação em relação } \\
\text { aos valores brutos. }\end{array}$ \\
\hline
\end{tabular}




\begin{tabular}{|c|c|c|c|}
\hline \multicolumn{4}{|c|}{ Quadro 4. continuação } \\
\hline $\begin{array}{l}\text { Autores, } \\
\text { ano }\end{array}$ & $\begin{array}{l}\text { Itens com alta correlação } \\
\qquad(\mathrm{r} \geq \mathbf{0 , 4 )}\end{array}$ & $\begin{array}{l}\text { Itens com baixa correlação } \\
\qquad(\mathrm{r}<\mathbf{0 , 4 )}\end{array}$ & Observações \\
\hline $\begin{array}{l}\text { Barbieri et } \\
\text { al., } 2012^{53}\end{array}$ & $\begin{array}{l}\text { Energia; Lipídeo; Carboidrato; Fibras; } \\
\text { Niacina. }\end{array}$ & $\begin{array}{l}\text { Proteína; Colesterol; Vitamina A; } \\
\text { Vitamina C; Vitamina E; Ácido } \\
\text { Fólico; Tiamina; Piridoxina; } \\
\text { Riboflavina; Cálcio; Potássio; } \\
\text { Zinco; Ferro; Magnésio; Fósforo; } \\
\text { Cobre. }\end{array}$ & $\begin{array}{l}\text { QFCA validado para os dois primeiros } \\
\text { trimestres da gestação (valores não } \\
\text { apresentados) e para todo o período } \\
\text { gestacional (valores apresentados) } \\
\text { cujos resultados de correlação são } \\
\text { diferentes. }\end{array}$ \\
\hline $\begin{array}{l}\text { Zanolla et } \\
\text { al., } 2009^{54}\end{array}$ & $\begin{array}{l}\text { Energia; Proteína; Lipídeo; } \\
\text { Carboidrato; Vitamina A; Vitamina } \\
\text { C; Cálcio. }\end{array}$ & - & $\begin{array}{l}\text { A validade relativa mostrou-se } \\
\text { razoável, especialmente para os } \\
\text { macronutrientes e vitamina C. }\end{array}$ \\
\hline $\begin{array}{l}\text { Machado et } \\
\text { al., } 2012^{55}\end{array}$ & $\begin{array}{l}\text { Bebidas alcoólicas; Biscoitos e bolos; } \\
\text { Cereais integrais; Folhosos; Frutas e } \\
\text { suco natural; Leguminosas; Leite e } \\
\text { derivados integrais; Leite e derivados } \\
\text { light; Pães; Sopas e legumes. }\end{array}$ & $\begin{array}{l}\text { Bebidas não-alcoólicas; Carnes } \\
\text { brancas; Carnes vermelhas; } \\
\text { Doces e guloseimas; Embutidos } \\
\text { e presuntos; Raízes e tubérculos; } \\
\text { Salgados. }\end{array}$ & $\begin{array}{l}\text { Ambos os questionários produziram } \\
\text { tanto estimativas de ingestão mais altas } \\
\text { como mais baixas do que a média dos } \\
\text { R24h. }\end{array}$ \\
\hline $\begin{array}{l}\text { Komatsu et } \\
\text { al., } 2013^{56}\end{array}$ & Energia. & $\begin{array}{l}\text { Proteína; Lipídeo; Carboidrato; } \\
\text { Fibras. }\end{array}$ & $\begin{array}{l}\text { Houve tendência à superestimação } \\
\text { nos dados sobre a energia e nutrientes, } \\
\text { exceto lipídeos. }\end{array}$ \\
\hline $\begin{array}{l}\text { Scagliusi et } \\
\text { al., } 2011^{25}\end{array}$ & $\begin{array}{l}\text { Energia; Proteína; Gordura } \\
\text { saturada; Colesterol; Fibras; Niacina; } \\
\text { Riboflavina; Cianocobalamina; Ácido } \\
\text { Fólico; Cálcio; Zinco; Ferro. }\end{array}$ & $\begin{array}{l}\text { Lipídeo; Carboidrato; Vitamina A; } \\
\text { Vitamina C; Vitamina E; Tiamina; } \\
\text { Piridoxina; Magnésio. }\end{array}$ & $\begin{array}{l}\text { Os gráficos de Bland-Altman } \\
\text { indicaram boa concordância para } \\
\text { quase todos os nutrientes. }\end{array}$ \\
\hline $\begin{array}{l}\text { Vian et al., } \\
2013^{26}\end{array}$ & $\begin{array}{l}\text { Polifenóis (QFCA vs. R24h, QFCA vs. } \\
\text { R3d) }\end{array}$ & $\begin{array}{l}\text { Polifenóis (QFCA vs. excreção } \\
\text { urinária de polifenóis) }\end{array}$ & $\begin{array}{l}\text { Os resultados foram ajustados pelo } \\
\text { Índice de Massa Corporal e pela idade } \\
\text { gestacional. A validade foi estabelecida } \\
\text { considerando o QFCA aplicado no } \\
\text { primeiro momento. }\end{array}$ \\
\hline $\begin{array}{l}\text { Molina et } \\
\text { al., } 2013^{57}\end{array}$ & $\begin{array}{l}\text { Energia; Lipídeo; Carboidrato; Fibras; } \\
\text { Vitamina C; Vitamina E; Cálcio; } \\
\text { Potássio; Zinco. }\end{array}$ & $\begin{array}{l}\text { Proteína; Vitamina A; Ferro; } \\
\text { Selênio. }\end{array}$ & $\begin{array}{l}\text { QFCA considerado de validade } \\
\text { relativa razoável para energia, } \\
\text { macronutrientes, cálcio, potássio, } \\
\text { vitamina E e vitamina C por meio de } \\
\text { estudo multicêntrico em seis capitais } \\
\text { das Regiões Sul, Sudeste e Nordeste. }\end{array}$ \\
\hline
\end{tabular}

Legenda: QFCA - Questionário de Frequência de Consumo Alimentar; r - Coeficiente de correlação; R24h- Recordatório de 24 horas; R3dRecordatório de três dias.

dade na entrevista e dificuldade de precisão da quantidade ingerida, potencializadas por características específicas dos idosos ${ }^{59}$.

Assim, como há a necessidade dos diferentes grupos etários serem contemplados em estudos de validação, é necessária a realização de estudos em todas as regiões do Brasil, de forma tal que possibilite discriminar diferenças entre populações, tendo em vista, principalmente, que na re- gião Norte foi encontrado um único estudo. No Brasil, na área de alimentação e nutrição, existe uma distribuição desigual da base técnico-científica na qual as regiões Norte e Nordeste são as mais desfavorecidas ${ }^{60,61}$. Para a redução dessas desigualdades, os investimentos, o uso adequado dos recursos e o incentivo à pesquisa e à formação parecem ser o caminho ainda a ser percorrido ${ }^{62}$. 
Ao analisar os resultados dos estudos de validação de QFCA, observou-se que os coeficientes de correlação dos nutrientes diferem entre os mesmos e que nem todos os instrumentos atingiram a correlação esperada. Isso pode estar relacionado com os objetivos de cada estudo. De acordo com Gorgojo Jiménez e Marín-Moreno ${ }^{63}$, o formato e a estratégia de aplicação de um questionário são determinados pelo pesquisador em função dos objetivos a serem alcançados, podendo interessar a análise de determinados nutrientes em particular. A variedade de objetivos pode pressupor a diversidade de formatos e estratégias de aplicação dos questionários incluídos na revisão. Sendo assim, é responsabilidade individual do pesquisador a escolha do melhor QFCA, considerando, ainda, os resultados obtidos nos estudos.

Em linhas gerais, verifica-se que, nos estudos de validação desenvolvidos no Brasil, os QFCA apresentam-se satisfatórios para avaliar energia, carboidratos, fibras, cálcio e vitamina C. A utilização do QFCA, validado no estudo de Henn et al. $2010^{20}$, impetra avaliar apropriadamente esse conjunto de nutrientes na sua associação com a saúde de adolescentes, adultos e idosos. O mesmo pode ser obtido em adolescentes com a aplicação do QFCA, validado no estudo de Slater et al. ${ }^{14}$, e em adultos com a aplicação do QFCA, validado por Molina et al. ${ }^{57}$. Considerando insatisfatórios os resultados das correlações, há que ressaltar a importância do desenvolvimento e validação de QFCA direcionados a micronutrientes específicos, principalmente o ferro. Além de ter sido o micronutriente que se apresentou com baixa correlação em maior quantidade de estudos, o ferro constitui o fator mais importante associado à anemia, a qual representa a carência nutricional de maior prevalência no mundo e no Brasil, acometendo indivíduos das mais diversas condições biológicas/fisiológicas (crianças, adolescentes, mulheres em idade fértil, gestantes, idosos) com graves consequências clínicas na saúde das pessoas afetadas ${ }^{64}$.

Os resultados sistematizados evidenciam a necessidade de, no Brasil, os pesquisadores continuarem investindo no desenvolvimento de métodos práticos, válidos e viáveis para mensurar de maneira fidedigna a ingestão alimentar. A relevância das investigações entre a associação da dieta e o desenvolvimento de doenças crônicas não transmissíveis é considerada irrefutável, pois as mesmas contribuem para o conhecimento dos processos etiológicos envolvidos em doenças de impacto na saúde pública ${ }^{65}$, em sintonia com as evidências empíricas sobre marcadores de alimentação não saudável, inclusive em crianças e adolescentes $^{66,67}$. No Brasil, em 2007, foi observado que $72 \%$ das mortes foram atribuídas às doenças crônicas não transmissíveis ${ }^{68}$. Prevalências elevadas de sobrepeso e obesidade têm sido verificadas tanto em crianças quanto em adolescentes e adultos ${ }^{69,70}$. O número de casos de diferentes tipos de câncer também está em aumento no Brasil, com proporções desiguais, no Nordeste, Sul e Centro-Oeste ${ }^{71}$. Consideramos que a análise dos métodos utilizados nos estudos desta revisão sobre o desenvolvimento e validação de QFCA fornece subsídios suficientes para os desafios colocados. Observa-se, em geral, que as principais diferenças metodológicas entre os estudos, para o desenvolvimento dos QFCA, estão na elaboração das listas de alimentos, na definição do tamanho das porções, no tempo precedente de interesse e nas categorias para determinar a frequência de ingestão.

O R24h é um método de fácil aplicação e baixo custo e, por isso, bastante utilizado em estudos de consumo alimentar ${ }^{4,72}$. A baixa correlação entre os erros de medição nas estimativas de nutrientes ou grupos de alimentos explica a preferência relacionada à utilização do R24h como método fonte de informação para a elaboração das listas dos alimentos. Erros estes que ocorrem, principalmente, por limitações da utilização de listas fixas de alimentos, viés de memória, estimativa das porções e entendimento das perguntas ${ }^{59}$.

Block et al ${ }^{35}$ têm sido a referência mais utilizada na elaboração de novas listas de alimentos ${ }^{6}$. Para o cálculo da contribuição percentual do item alimentar em relação à energia e nutrientes, Block et al. ${ }^{35}$ propõem, considerando as informações geradas por vários RA/DA ou R24h, o cálculo da razão entre a quantidade de energia ou nutriente de cada alimento e o total de energia ou nutriente fornecido por todos os alimentos, multiplicado por 100. O cálculo possibilita o agrupamento dos itens alimentares para definir quais seriam incluídos na lista. Essa estratégia tem a vantagem de tornar improvável a omissão de algum item importante na lista de alimentos ${ }^{63}$.

Anjos et al. ${ }^{9}$ evidenciaram a necessidade de desenvolver melhorias em vários dos procedimentos de determinação da ingestão alimentar das populações, entre eles a informação sobre o tamanho das porções. Em relação ao QFCA, apesar da sua utilização frequente nos estudos, existem divergências quanto à necessidade da definição do tamanho da porção ${ }^{6}$. Argumenta-se que a coleta dessa informação possibilita obter a 
frequência de ingestão como variável contínua e não categórica ${ }^{73}$, porém, que pouco contribui para melhorar a qualidade do questionário, havendo a possibilidade de coletar apenas a informação qualitativa da dieta ${ }^{6}$. As porções alimentares padronizadas representam medidas de conveniência e aproximação que não correspondem às quantidades que habitualmente são ingeridas por grupos populacionais diversos ${ }^{73}$. Neste aspecto, a introdução de registros fotográficos pode facilitar a identificação mais aproximada da real porção ingerida ${ }^{9}$, ajudando na quantificação da frequência de ingestão com maior qualidade.

Admite-se a avaliação do último ano ou dos últimos seis meses como os mais apropriados em relação ao tempo precedente de interesse em um QFCA. A escolha de um maior período possibilita captar a variabilidade sazonal dos itens alimentares, principalmente em países de zona tempera$\mathrm{da}^{59}$. Nesse contexto, a utilização de tempos precedentes curtos em alguns questionários, incluídos nos estudos desta revisão ${ }^{12,17,28}$, deve ser analisada com cautela, uma vez que isso pode comprometer o seu desempenho na avaliação da ingestão alimentar habitual. Não obstante, há que considerar que o tempo pregresso se estabelece em função do desenho de estudo, os nutrientes de interesse, o grupo populacional e o tempo de exposição ao fator dietético ${ }^{6,63}$. Cabe ressaltar, ainda, a necessidade de os artigos apresentarem tal informação.

Ainda, no contexto da validação, é importante ressaltar que os itens alimentares e as categorias para determinar a frequência de ingestão, aspectos diretamente relacionados ao objetivo do estudo, constituem a base principal no desenho de um $\mathrm{QFCA}^{73}$. As categorias para determinar a frequência de ingestão são de grande utilidade para estimar adequadamente a dieta habitual e identificar grupos de indivíduos com ingestão inadequada' ${ }^{9}$ A quantidade de itens na lista de alimentos é importante, na medida em que questionários muito extensos podem tornar a entrevista cansativa ou elevar a ausência de respostas, e questionários muito curtos podem não representar adequadamente a ingestão alimen$\operatorname{tar}^{9,74}$. Dessa forma, observa-se que a utilização de extremos, tanto do número de categorias de frequência quanto do número de itens da lista de alimentos, deve ser cuidadosamente ponderada tendo em vista que esses casos poderiam comprometer os resultados da pesquisa.

$\mathrm{Na}$ validação de um QFCA, recomenda-se o RA/DA como método dietético de referência ${ }^{6}$. Esse método apresenta a vantagem de tornar improváveis erros correlacionados aos do $\mathrm{QFCA}^{59}$.
No entanto, a maior parte dos estudos incluídos nesta revisão utilizou o R24h como método de referência, fato possivelmente justificável por ser um instrumento com vantagens de utilização (rápida aplicação, baixo custo, recordação recente da ingestão) $)^{4,72}$.

Recentemente, tem se indicado a validação de QFCA pela correlação entre três variáveis (QFCA, método de referência de ingestão alimentar, biomarcador), denominado método das tríades $^{47,75}$, usado em dois ${ }^{26,47}$ dos estudos mais atuais que foram revisados. A possibilidade de baixa associação entre os instrumentos dietéticos e biomarcadores, como no caso do estudo que analisou a ingestão dietética e a excreção urinária de polifenóis ${ }^{26}$, explica-se pela influência de outros fatores, além do consumo alimentar, como as diferenças individuais na absorção, metabolismo e adaptações bioquímicas, segundo os próprios autores. Porém, o uso de biomarcadores apresenta como vantagem a ausência de erros semelhantes aos do QFCA e boa relação com a real ingestão alimentar ${ }^{59}$. Assim, no método das tríades, a correlação entre as três variáveis e a ingestão real, por meio do coeficiente de validade, garante a acurácia do método dietético ${ }^{75}$. A pesquisa no Brasil com o uso dessa técnica ainda é incipiente, sendo necessária sua incorporação nos estudos de validade de QFCA em diferentes contextos e objetivos.

A limitação da presente revisão está centrada no fato da elaboração dos QFCA e respectivos estudos de validação diferirem em características como os nutrientes ou alimentos de interesse, critérios para a elaboração das listas de alimentos, intervalo de tempo da aplicação do método de referência e utilização ou não de dados de-atenuados e/ou ajustados pela energia. Assim, como esses fatores podem afetar as medidas de correlação, a descrição sobre a validade expressa na revisão não constitui uma informação sistematizada. Além disso, os ensaios de reprodutibilidade e calibração não foram tratados neste trabalho, os quais também devem ser considerados nas escolhas dos instrumentos.

\section{Conclusões}

A partir dos estudos identificados nesta revisão foi possível observar diferenças inter-regionais nas publicações; diferenças metodológicas, tanto no desenvolvimento do questionário (elaboração das listas de alimentos, definição do tamanho das porções, tempo precedente de interesse, ca- 
tegorias para determinar a frequência de ingestão) como na validação (tempo da aplicação do método de referência, utilização ou não de dados de-atenuados e/ou ajustados pela energia); e ausência de instrumentos específicos e validados para crianças menores de cinco anos, sendo adultos e adolescentes os grupos populacionais mais contemplados nos estudos de validação. Dessa forma, verifica-se a necessidade da condução de estudos que supram essas lacunas. O rigor metodológico e os resultados estatísticos satisfatórios observados nos estudos desta revisão garantem a adequação dos QFCA validados para as respectivas populações alvo. Há que considerar que essa adequação está condicionada àqueles nutrientes com alta correlação, indicada, principalmente, para carboidrato, fibras, cálcio e vitamina C, além da energia.

\section{Colaboradores}

Figueroa Pedraza D concebeu o objetivo e participou da busca bibliográfica, interpretação dos resultados, redação e revisão do artigo; Menezes TN participou da busca bibliográfica, interpretação dos resultados, redação e revisão do artigo.

\section{Referências}

1. Lobo AS. DAFA (Dia típico de atividades físicas e alimentação): Reprodutibilidade e validade concorrente relativa ao consumo alimentar [tese]. Florianópolis: Universidade Federal de Santa Catarina; 2003.

2. Slater B, Philippi ST, Marchioni DML, Fisberg RM. Validação de questionários de freqüência alimentar QFA: considerações metodológicas. Rev Bras Epidemiol 2003; 6(3):200-208.

3. Cavalcante AAM, Priore SE, Franceschini SCC. Estudos de consumo alimentar: aspectos metodológicos gerais e o seu emprego na avaliação de crianças e adolescentes. Rev Bras Saude Matern Infant 2004; 4(3):229-240.

4. Costa AGV, Priore SE, Sabarense CM, Franceschini SCC. Questionário de frequência de consumo alimentar e recordatório de 24 horas: aspectos metodológicos para avaliação da ingestão de lipídeos. Rev Nutr 2006; 19(5):631-641.

5. Barbosa RMS, Soares EA, Lanzillotti HS. Avaliação da ingestão de nutrientes de crianças de uma creche filantrópica: aplicação do Consumo Dietético de Referência. Rev Bras Saude Matern Infant 2007; 7(2):159-166.

6. Colucci ACA, Slater B, Philippi ST. Etapas para desenvolvimento de um questionário de freqüência alimentar. Rev Bras Cienc Saude 2005; 6:7-12.

7. Willett WC, Lenart E. Reproducibility and validity of food-frequency questionnaires. In: Willett WC. Nutritional Epidemiology. 2a ed. New York: Oxford University Press; 1998. p. 101-47.

8. Block G, Hartman AM, Dresser CM, Carroll MD, Gannon J, Gardner L. A data-based approach to diet questionnaire design and testing. Am J Epidemiol 1986; 124(3):453-469.

9. Anjos LA, Souza DR, Rossato SL. Desafios na medição quantitativa da ingestão alimentar em estudos populacionais. Rev Nutr 2009; 22(1):151-161.

10. Sichieri R, Everhart JE. Validity of a Brazilian food frequency questionnaire against dietary recalls and estimated energy intake. Nutr Res 1998; 18(10):1649-1659.
11. Cardoso MA, Stocco PR. Desenvolvimento de um questionário quantitativo de frequência alimentar em imigrantes japoneses e seus descendentes residentes em São Paulo, Brasil. Cad Saude Publica 2000; 16(1):107-114.

12. Salvo VLMA, Gimeno SGA. Reprodutibilidade e validade do questionário de frequência de consumo de alimentos. Rev Saude Publica 2002; 36(4):505-512.

13. Ribeiro AB, Cardoso MA. Construção de um questionário de freqüência alimentar como subsídio para programas de prevenção de doenças crônicas não transmissíveis. Rev Nutr 2002; 15(2):239-245.

14. Slater B, Fisberg RM, Philippi ST, Latorre MRO. Validation of a semi-quantitative adolescents food frequency questionnaire applied at a public school in São Paulo, Brazil. Eur J Clin Nutr 2003; 57(5):629-635.

15. Fornés NS, Stringhini ML, Elias BM. Reproducibility and validity of a food-frequency questionnaire for use among low-income Brazilian workers. Public Health Nutr 2003; 6(8):821-827.

16. Lima FEL, Fisberg RM, Slater B. Desenvolvimento de um questionário quantitativo de frequência alimentar (QQFA) para um estudo caso controle de dieta e câncer de mama em João Pessoa PB. Rev Bras Epidemiol 2003; 6(4):373-379.

17. Sales RL, Silva MMS, Costa NMB, Euclydes MP, Eckhardt VF, Rodrigues CMA, Tinôco ALA. Desenvolvimento de um inquérito para avaliação da ingestão alimentar de grupos populacionais. Rev Nutr 2006; 19(5):539-552.

18. Araújo MC, Ferreira DM, Pereira RA. Reprodutibilidade de questionário semiquantitativo de frequência alimentar elaborado para adolescentes da Região Metropolitana do Rio de Janeiro, Brasil. Cad Saude Publica 2008; 24(12):2775-2786

19. Fisberg RM, Colucci ACA, Morimoto JM, Marchioni DML. Questionário de freqüência alimentar para adultos com base em estudo populacional. Rev Saude Publica 2008; 42(3):550-554. 
20. Henn RL, Fuchs SC, Moreira LB, Fuchs FD. Development and validation of a food frequency questionnaire (FFQ-Porto Alegre) for adolescent, adult and elderly populations from Southern Brazil. Cad Saude Publica 2010; 26(11):2068-2079.

21. Ferreira MG, Silva, Schmidt FD, Silva RMBG, Sichieri R, Guimarães LV, Pereira RA. Desenvolvimento de Questionário de Frequência Alimentar para adultos em amostra de base populacional de Cuiabá, Região Centro-Oeste do Brasil. Rev Bras Epidemiol 2010; 13(3):413-424.

22. Oliveira T, Marquitti FD, Carvalhaes MABL, Sartorelli DS. Desenvolvimento de um Questionário Quantitativo de Freqüência Alimentar (QQFA) para gestantes usuárias de unidades básicas de saúde de Ribeirão Preto, São Paulo, Brasil. Cad Saude Publica 2010; 26(12):2296-2306.

23. Anjos LA, Wahrlich, V, Vasconcellos MTL, Souza DR, Olinto MTA, Waissmann W, Henn RL, Rossato SL, Lourenço AE, Bressan AW. Development of a food frequency questionnaire in a probabilistic sample of adults from Niterói, Rio de Janeiro, Brazil. Cad Saude Publica 2010; 26(11):2196-2204.

24. Carvalho FS, Laer NMV, Sachs A, Salvo VLMA, Coelho LC, Santos GMS, Akutsu RC, Asakura L. Desenvolvimento e pré-teste de um questionário de frequência alimentar para graduandos. Rev Nutr 2010; 23(5):847857.

25. Scagliusi FB, Garcia MT, Indiani ALC, Cardoso MA. Relative validity of a food-frequency questionnaire developed to assess food intake of schoolchildren living in the Brazilian Western Amazon. Cad Saude Publica 2011; 27(11):2197-2206.

26. Vian I, Zielinsky P, Zilio AM, Mello A, Lazzeri B, Oliveira A, Lampert KV, Piccoli A, Nicoloso LH, Bubols GB, Garcia SC. Development and validation of a food frequency questionnaire for consumption of polyphenol-rich foods in pregnant women. Matern Child Nutr 2013; 15:1-14.

27. Molina MCB, Faria CP, Cardoso LO, Drehmer M, Velasquez-Meléndez JG, Gomes ALC, Melere C, Diniz MFHS, Sichieri R, Benseñor IJM. Diet assessment in the Brazilian Longitudinal Study of Adult Health (ELSA-Brasil): Development of a food frequency questionnaire. Rev Nutr 2013; 26(2):167-176.

28. Carvalho CMRG, Nogueira AMT, Teles JBM, Paz SMR, Sousa RML. Consumo alimentar de adolescentes matriculados em um colégio particular de Teresina, Piauí, Brasil. Rev Nutr 2001; 14(2):85-93.

29. Colucci ACA, Philippi ST, Slater B. Desenvolvimento de um questionário de frequência alimentar para avaliação do consumo alimentar de crianças de 2 a 5 anos de idade. Rev Bras Epidemiol 2004; 7(4):393-401.

30. Furlan-Viebig R, Pastor-Valero M. Desenvolvimento de um questionário de frequência alimentar para o estudo da dieta e doenças não transmissíveis. Rev Saude Publica $2004 ; 38(4): 581-584$

31. Fornés NS, Stringhini MLF. Development of a food frequency questionnaire (FFQ) and characterization of the food pattern consumption for low - income workers in the city of Goiânia, Goiás State State, Brazil. Acta Sci Health Sci 2005; 27(1):69-75.

32. Araújo MC, Veiga GV, Sichieri R, Pereira RA. Elaboração de questionário de frequência alimentar semiquantitativo para adolescentes da região metropolitana do Rio de Janeiro, Brasil. Rev Nutr 2010; 23(2):179-189.
33. Gonçalves FA, Pechansky F, Slavutzky SMB. Desenvolvimento de um Questionário de Frequência Alimentar (QFA-açúcar) para quantificar o consumo de sacarose. Rev HCPA 2011; 31(4):428-436.

34. Instituto Brasileiro de Geografia e Estatística (IBGE). Metodologia do Estudo Nacional da Despesa Familiar - ENDEF. Objetivos, descrição e metodologia usada no ENDEF. Rio de Janeiro: IBGE; 1993.

35. Block G, Dresser CM, Hartman AM, Carroll MD. Nutrient sources in the American diet: quantitative data from the NHANES II survey. II. Macronutrients and fats. Am J Epidemiol 1985; 122(1):27-40.

36. Block G, Dresser CM, Hartman AM, Carroll MD. Nutrient sources in the American diet: quantitative data from the NHANES II survey. I. Vitamins and minerals. Am J Epidemiol 1985; 122(1):13-26.

37. Nelson M. The validation of dietary assessment. In: Magetts B, Nelson M, editors. Design concepts in nutrition epidemiology. $2^{\text {a }}$ ed. New York: Oxford University Press; 1994 p. 241-72.

38. United States Department of Agriculture. USDA Database for the Flavonoid Content of Selected Foods Release; 2007. [acessado (informar ano mês dia)]. Disponível em: http://www.nal.usda.gov/fnic/foodcomp/ Data/Flav/Flav02-1.pdf.

39. Faller ALK, Fialho E. Polyphenol availability in fruits and vegetables consumed in Brazil. Rev Saude Publica 2009; 43(2):211-218.

40. Howe GR, Harisson L, Jain M. A short diet history for assessing dietary exposure to n-nitrosamines in epidemiologic studies. Am J Epidemiol 1986; 124(4):595-601.

41. Ribeiro AC, Sávio KEO, Rodrigues MLCF, Costa THM, Schmitz BAS. Validação de um questionário de frequência de consumo alimentar para população adulta. Rev Nutr 2006; 19(5):553-562.

42. Giacomello A, Schmidt MI, Nunes MAA, Duncan BB, Soares RM, Manzolli P, Camey S. Validação relativa de Questionário de Frequência Alimentar em gestantes usuárias de serviços do Sistema Único de Saúde em dois municípios no Rio Grande do Sul, Brasil. Rev Bras Saude Matern Infant 2008; 8(4):445-454.

43. Cardoso MA, Kida AA, Tomita LY, Stocco PR. Reproducibility and validity of a food frequency questionnaire among women of Japanese ancestry living in Brazil. Nutr Res 2001; 21(5):725-733.

44. Cardoso MA, Tomita LY, Laguna EC. Assessing the validity of a food frequency questionnaire among low -income women in São Paulo, southeastern Brazil. Cad Saude Publica 2010; 26(11):2059-2067.

45. Monteiro JP, Sartorelli DS, Vieira MNCM, Bianchi MLP. Validation of a food frequency questionnaire for assessing dietary nutrients in Brazilian children 5 to 10 years of age. Nutrition 2008; 24(5):427-432.

46. Voci SM, Enes CC, Slater B. Validação do Questionário de Frequência Alimentar para Adolescentes (QFAA) por grupos de alimentos em uma população de escolares. Rev Bras Epidemiol 2008; 11(4):561-572.

47. Slater B, Enes CC, López RV, Damasceno NR, Voci SM. Validation of a food frequency questionnaire to assess the consumption of carotenoids, fruits and vegetables among adolescents: the method of triads. Cad Saude Publica 2010; 26(11):2090-2100.

48. Lima FEL, Slater B, Latorre MRDO, Fisberg RM. Validade de um questionário quantitativo de frequência alimentar desenvolvido para população feminina no nordeste do Brasil. Rev Bras Epidemiol 2007; 10(4):483-490. 
49. Crispim SP, Ribeiro RCL, Panato E, Silva MMS, Rosado LEFP, Rosado GP. Validade relativa de um questionário de frequência alimentar para utilização em adultos. Rev Nutr 2009; 22(1):81-95.

50. Araújo MC, Yokoo EM, Pereira RA. Validation and calibration of semiquantitative food frequency questionnaire designed for adolescents. J Am Diet Assoc 2010; 110(8):1170-1177

51. Teixeira JA, Baggio ML, Giuliano AR, Fisberg RM, Marchioni DML. Performance of the quantitative food frequency questionnaire used in the Brazilian center of the prospective study "Natural History of HPV Infection in Men: the HIM Study". J Am Diet Assoc 2011; 111(7):1045-1051

52. Silva NF, Sichieri R, Pereira RA, Silva RMVG, Ferreira MG. Reproducibility, relative validity and calibration of a food frequency questionnaire for adults. Cad Saude Publica 2013; 29(9):1783-1794.

53. Barbieri P, Nishimura RY, Crivellentil LC, Sartorell DS. Relative validation of a quantitative FFQ for use in Brazilian pregnant women. Public Health Nut 2012; 16(8):1419-1426.

54. Zanolla AF, Olinto MTA, Henn RL, Wahrlich V, Anjos LA. Avaliação de reprodutibilidade e validade de um questionário de freqüência alimentar em adultos residentes em Porto Alegre, Rio Grande do Sul, Brasil. Cad Saude Publica 2009; 25(4):840-848.

55. Machado FCS, Henn RL, Olinto MTA, Anjos LA, Wahrlich V, Waissmann W. Reprodutibilidade e validade de um questionário de frequência alimentar por grupos de alimentos, em adultos da Região Metropolitana de Porto Alegre, Brasil. Rev Nutr 2012; 25(1):65-77.

56. Komatsu TR, Oku SK, Gimeno SGA, Asakura L, Coelho LC, Silva CVD, Akutsu RC, Sachs A. Validation of a quantitative food frequency questionnaire developed to under graduate students. Rev Bras Epidemiol 2013; 16(4):898-906.

57. Molina MCB, Benseñor IM, Cardoso LO, VelasquezMeléndez JG, Drehmer M, Pereira TSS, Faria CP, Melere C, Manato L, Gomes ALC; Fonseca MJM, Sichieri R. Reprodutibilidade e validade relativa do Questionário de Frequência Alimentar do ELSA-Brasil. Cad Saude Publica 2013; 29(2):379-389.

58. Kim DW, Oh SY, Kwon SO, Kim J. Comparison of validity of food group intake by food frequency questionnaire between pre- and post- adjustment estimates derived from 2-day 24-hour recalls in combination with the probability of consumption. Asian Pac J Cancer Prev 2012; 13(6):2655-2661.

59. Cardoso MA. Desenvolvimento, Validação e Aplicações de Questionários de Frequência Alimentar em Estudos Epidemiológicos. In: Kac G, Sichieri R, Gigante DP, organizadores. Epidemiologia nutricional. Rio de Janeiro: Atheneu; 2007. p. 201-211.

60. Kac G, Fialho E, Santos SMC. Panorama atual dos programas de pós-graduação em Nutrição no Brasil. Rev Nutr 2006; 19(6):771-784.

61. Canella DS, Silva ACF, Jaime PC. Produção científica sobre nutrição no âmbito da Atenção Primária à Saúde no Brasil: uma revisão de literatura. Cien Saude Colet 2013; 18(2):297-308.

62. Barros FAF. Os desequilíbrios regionais da produção técnico-científica. São Paulo Perspec 2000; 14(3):12-19.
63. Gorgojo Jiménez L, Martin-Moreno JM. Cuestionario de frecuencia de consumo alimentario. In: Majem LS, Bartrina JA, Verdú JM, organizadores. Nutrición y Salud Pública - Métodos, bases científicas y aplicaciones. Barcelona: Masson; 1995. p. 120-125.

64. Batista Filho M, Souza AI, Bresani CC. Anemia como problema de saúde pública: uma realidade atual. Cien Saude Colet 2008; 13(6):1917-1922.

65. Pereira RA, Sichieri R. Métodos de avaliação do Consumo de Alimentos. In: Kac G, Sichieri R, Gigante DP, organizadores. Epidemiologia nutricional. Rio de Janeiro: Atheneu; 2007. p. 181-200.

66. Malta DC, Sardinha LMV, Mendes I, Barreto SM, Giatti L, Castro IRR, Moura L, Dias AJR, Crespo C. Prevalência de fatores de risco e proteção de doenças crônicas não transmissíveis em adolescentes: resultados da Pesquisa Nacional de Saúde do Escolar (PeNSE), Brasil, 2009. Cien Saude Colet 2010; 15(Supl.2):3009-3019.

67. Costa FP, Machado SH. O consumo de sal e alimentos ricos em sódio pode influenciar na pressão arterial das crianças? Cien Saude Colet 2010; 15(Supl.1):1383-1389.

68. Schmidt MA, Duncan BB, Azevedo e Silva G, Menezes AM, Monteiro CA, Barreto SM, Chor D, Menezes PR. Doenças crônicas não transmissíveis no Brasil: carga e desafios atuais. Lancet 2011; 4:61-74.

69. Instituto Brasileiro de Geografia e Estatística (IBGE). Pesquisa de Orçamentos Familiares 2008-2009: antropometria e estado nutricional de crianças, adolescentes e adultos no Brasil. Rio de Janeiro: IBGE; 2010.

70. Instituto Brasileiro de Geografia e Estatística (IBGE) Pesquisa Nacional de Saúde do Escolar 2009: avaliação do estado nutricional dos escolares do $9^{\circ}$ ano do ensino fundamental: municípios das capitais e Distrito Federal. Rio de Janeiro: IBGE; 2010.

71. Instituto Nacional de Câncer (INCA). Estimativa 2010 incidência de câncer no Brasil. Rio de Janeiro: INCA 2009.

72. Buzzard M. 24-hours dietary recall and food record methods. In: Willett WC. Nutritional Epidemiology. $2^{\mathrm{a}}$ ed. New York: Oxford University Press; 1998. p. 50-73.

73. Tomita LY, Cardoso MA. Avaliação da lista de alimentos e porções alimentares de Questionário Quantitativo de Freqüência Alimentar em população adulta. Cad Saude Publica 2002; 18(6):1747-1756.

74. Chiara VL, Barros ME, Costa LP, Martins PD. Redução de lista de alimentos para questionário de freqüência alimentar: questões metodológicas na construção. Rev Bras Epidemiol 2007; 10(3):410-420.

75. Yokota RTC, Miyazaki ES, Ito MK. Applying the triads method in the validation of dietary intake using biomarkers. Cad Saude Publica 2010; 26(11):2027-2037.

Artigo apresentado em 27/08/2014

Aprovado em 05/11/2014

Versão final apresentada em 07/11/2014 